\title{
Evaluation of effectiveness of integration of eating awareness training and implementation intention model on Body Mass Index, Waist circumference, Mindfulness Eating, and Physical Activity in Obese Women
}

\begin{abstract}
Background and Objective: Obesity is a metabolic and medical condition in which adipose tissue accumulates too much in the body. The main purpose of current study is "evaluation of effectiveness of integration of eating awareness training and implementation intention model on body mass index, waist circumference, mindfulness eating, and physical activity in obese women."

Materials and Methods: The research method was semi-experimental with pretest, post-test and follow-up test design, and comparing them with a control group. The population of this study were obese women with a BMI higher or equal to 25 in Karaj in 1398. Forty-one subjects were randomly divided into two experimental and control groups according to the inclusion criteria and targeted sampling. Weight with digital scales, waist with meter tape, mindful eating questionnaire and physical activity with checklist, were assessed. MB_EAT was held during 12 sessions of 150 minutes each session and with the implementation intention model, daily planning for physical activity was done. Data were analyzed by mixed analysis, Shapiro-Wilk, Loon, Mohali sphericity, with significance level of $\mathrm{P}<0 / 001$. Finally, 35 people were analyzed.

Results: The results showed that the integration of implementation intention and mindfulness-based eating awareness training reduces the mean BMI in the post-test (71.57 \pm 0.6$)$ and follow-up $(69.78 \pm 0.97)$ compared to the pre-test $(77.00 \pm 1.05)$ and eat mindfulness eating in the post-test (53.52 \pm 0.80$)$ and follow up (53.21 $\pm 0.67)$ and increase the average physical activity in the post-test $(24.06 \pm 2.84)$ and follow up $(23.65 \pm 2.52)$ compared to the pre-test $(28.91 \pm 3.18) .(P=0.001)$. Conclusion: The result of integration of MB_EAT and implementation intention model was to increase people's ability to self-regulate and be aware of the body sensations and emotional symptoms of eating and doing physical activity on a daily basis, which eventually led to weight loss.

Keywords: Mindful Eating, Mindfulness, Implementation Intention, Body Mass Index, Waist circumference, Physical Activity.

Paper Type: Research Article.
\end{abstract}

Citation (Vancouver): Jassemi-Zergani M, Seirafi M, Taghdisi M, MalihiAlzuckerini S, Taghavi-Kojeidi h. Evaluation of effectiveness of integration of eating awareness training and implementation intention model on Body Mass Index, Waist circumference, Mindfulness Eating, and Physical Activity in Obese Women. Iran J Health Educ Health Promot. Spring 2021;9(1):94-109. [Persian]

> Citation (APA): Jassemi-Zergani M., Seirafi M., Taghdisi M., Malihi-Alzuckerini S., Taghavi-Kojeidi h. Evaluation of effectiveness of integration of eating awareness training and implementation intention model on Body Mass Index, Waist circumference, Mindfulness Eating, and Physical Activity in Obese Women. Iranian Journal of Health Education \& Health Promotion., 9(1), 94-109. [Persian]
Mona Jassemi-Zergani

Ph.D. Student in Health Psychology, Karaj Branch, Islamic Azad University, Karaj, Iran.

Mohammad-Reza Seirafi Assistant Professor, Karaj Branch, Islamic Azad University, Karaj, Iran.

Mohammad-Hosein Taghdisi * Health Promotion PhD. health-and-medical-engineering-andpsychology Public Health Department, School of Health and Medical Engineering, Islamic Azad University Tehran Medical Sciences, Tehran, Iran. (corresponding author)

taghdisimh@gmail.com

Saeid Malihi-Alzuckerini Assistant Professor, Karaj Branch, Islamic Azad University, Karaj, Iran.

Habibeh Taghavi-Kojeidi Assistant Professor, Alborz University of Medical Sciences and Health Services, Karaj, Iran

\section{Received: 2020/11/28}

Accepted: 2021/01/05

Doi: 10.29252/ijhehp.9.1.94 


\section{بروسى اثر بخشى تلفيق آموزش خوردن آكاهانه و مدل قصد تحقق رفتار بر، شاخص توده بلدن}

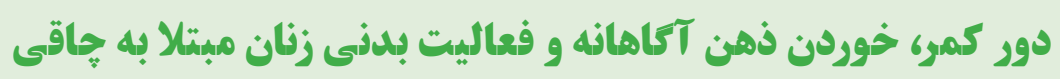

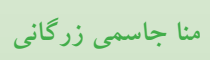

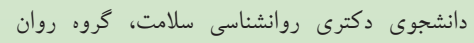

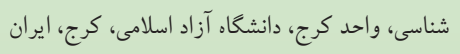

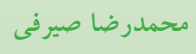

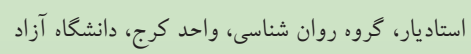
اسلامى، كرج، ايران.

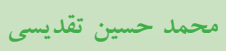

استاد ارتقاء سلامت، كروه يهداشت عمومى، دانشكده بهداشت و مهندسى يزشكى، دانشكاء علوم يزشكى آزاد آنساد

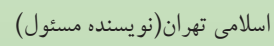
taghdisimh@gmail.com

سعيد مليحى الذاكرينى استى

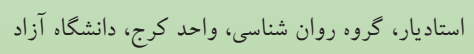

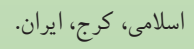
حبيبه تقوى كجيدى ارئ استاديار، دانشكاء علوم يزشكى البرز، كرج. ايران

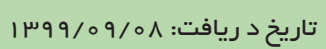
تاريخ يذيرش:

\section{0}

زمينه و هدف : امروزه هاقى به عنوان يكى از مشكلات اصلى تهديد كننده سلامت و عمده ترين بيمارى

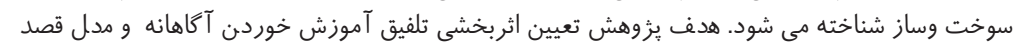

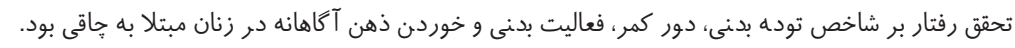

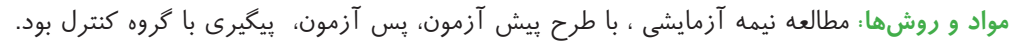

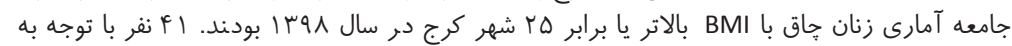

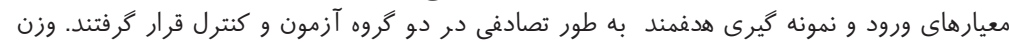

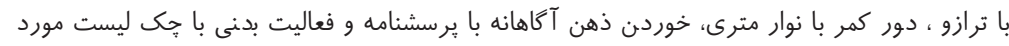

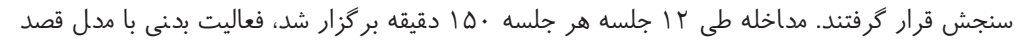

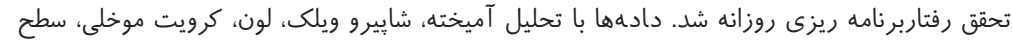

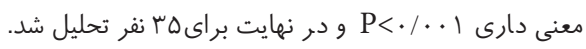

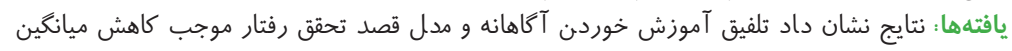

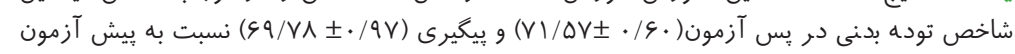

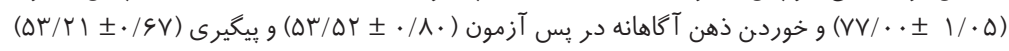

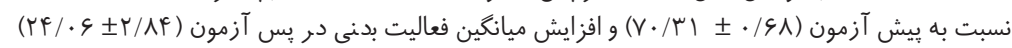

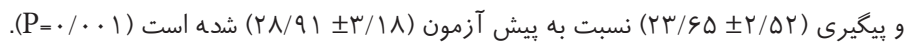

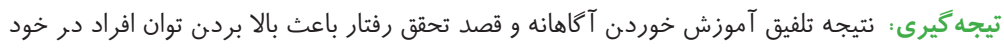

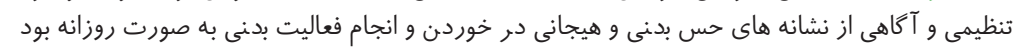

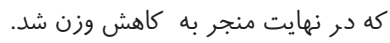

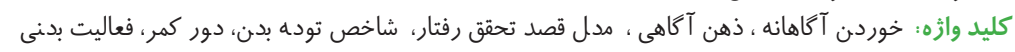

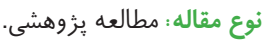

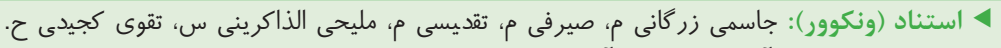

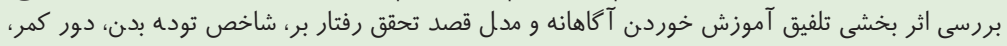

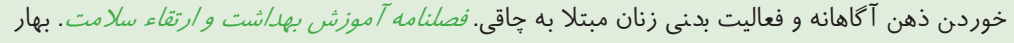
. .9-9F: (1)9:1F. .

4 استناد (APA): جاسمى زر كانى، منا؛ صيرفى، محمدر ضا؛ تقديسى، محمدحسين؛ مليحى الذاكرينى، سعيد؛

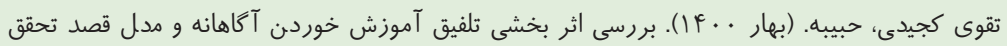

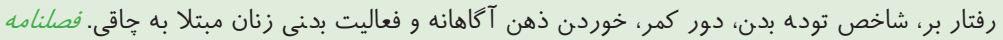

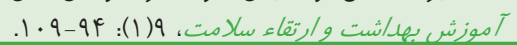


قلبى - عروقى؛ دستكاء كوارش و كبد جرب؛ مفصلى و عضلانى؛

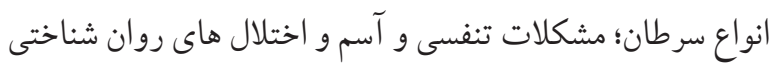

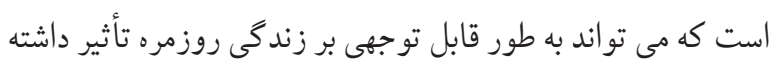

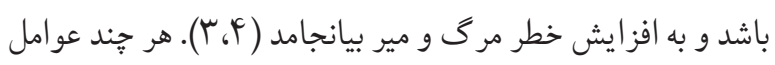
زنتيكى و زيستى بر ميزان غذايى كه خورده مىشود تاثير كذارند،

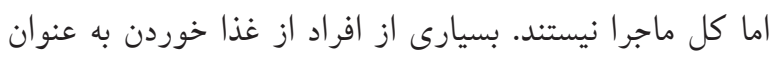

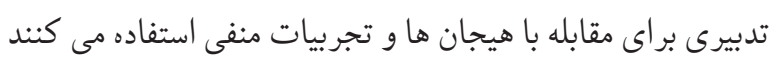

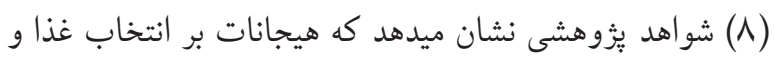

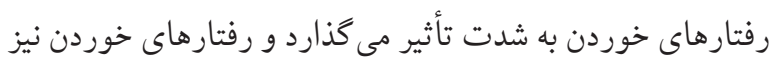

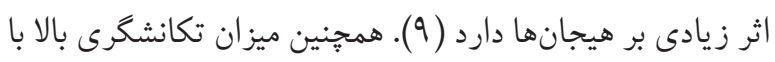

جاقى شكمى، اضافه وزن و هاقى همبستكى دارد (· • (1).

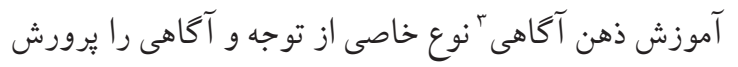

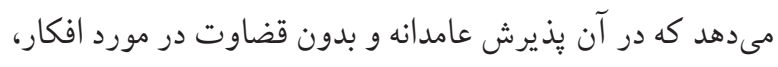
احساسات و حسهاى بدنى كه در هر لحظه آكاهى را بو جود مى آورد

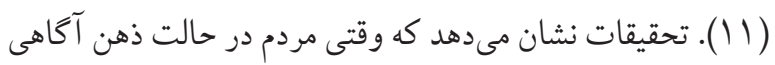

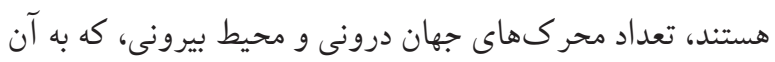

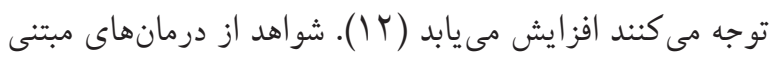

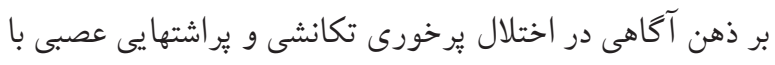

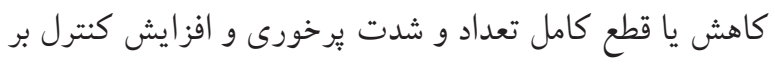

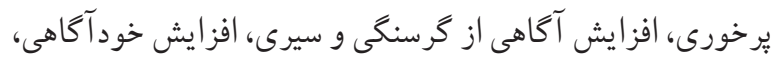

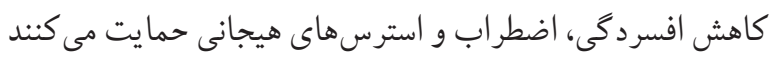

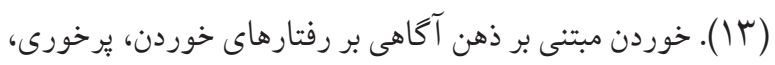

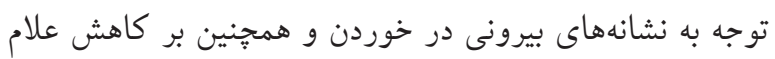

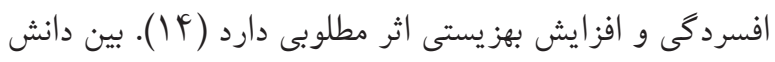

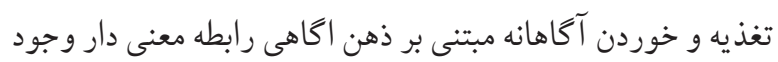

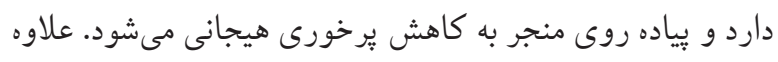

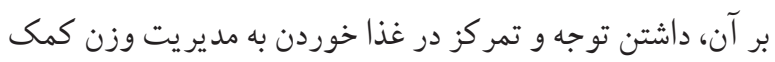

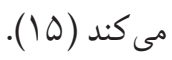
"آموزش خوردن آكاهانه مبتنى بر ذهن آكاهى (MB_EAT)

3. Mindfulness

4. Mindfulness Based-Eating Awareness Training
جاقى بيمارى سوخت و ساز و وضيعت يُشكى است كه طى آن

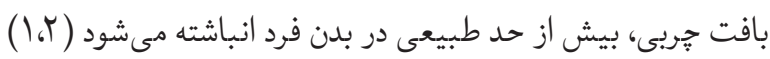

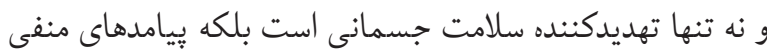
روانى، اقتصادى، اجتماعى را موجب مى ششود كه مستلنزم هزينههاى درمانى و ويشخيرى است كه از اين رو بايد مورد توجه قرار كيرد.

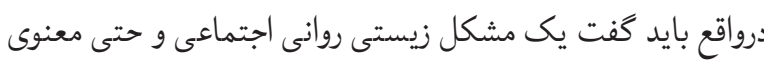

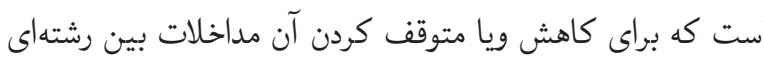

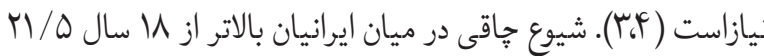

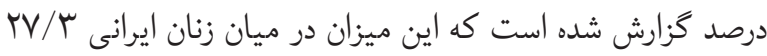

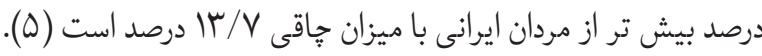

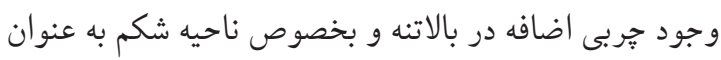
جاقى شكمى شناخته مى شود كه بيش اكهى مستقلى براى بيمارى هاى

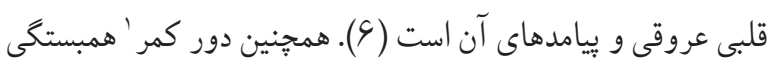

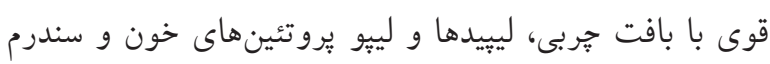

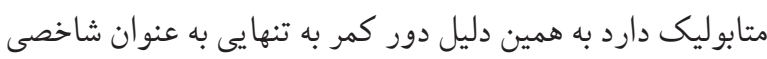

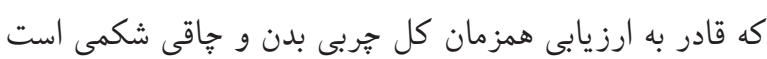

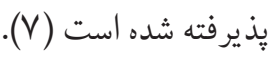
شاخص توده بدنى ' را براى اندازه كيرى ميزان جاقى مطرح

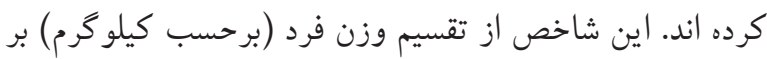

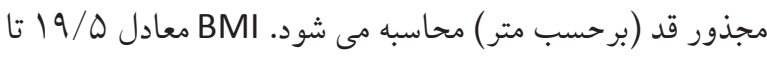

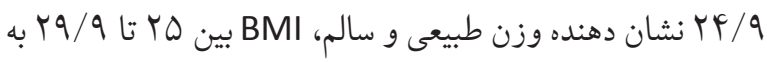

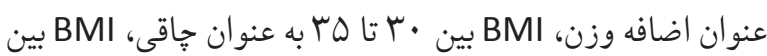

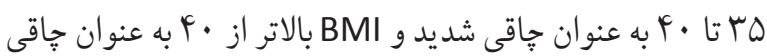
مرضى در نظر كرفته مى شود كه با افزايش بسيار زياد خطر همراه

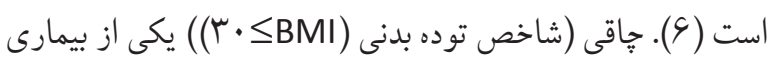

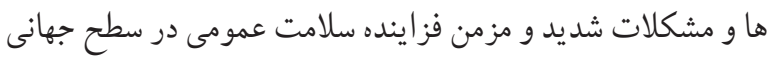

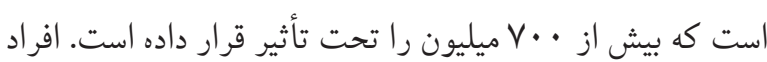

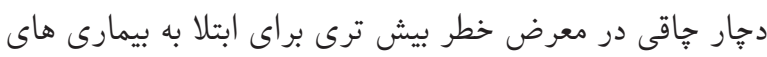
1. Waist circumference 2. body mass index 
شود، فرد را در گير اعمالى كرده كه تبديل هدف به عمل را تسهيل

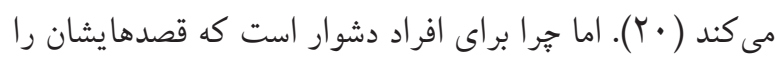
عملى كنند؟ سه فر ايند سبب نا هماهنگى ميان قصد و رفتار است. اولين فرايند به ماند گارى قصد بر مى گردد. به اين معنى كه بيشتر

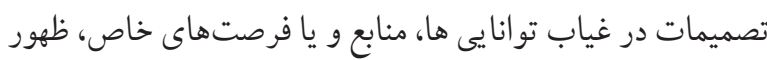
نمى يابند. يعنى اينكه قصد رفتارى زمانى عملى مىشود كه فرد كنترل واقعى بر روى تحقق رفتار داشته باشد (Y) (Y). فرايند دوم

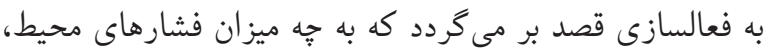
مسير يا شدت قصد اصلى را نسبت به قصدهاى ديخر تغيير مىدهد.

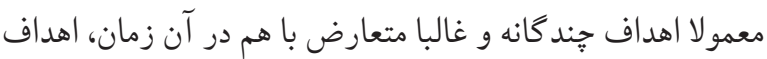
و رفتارهاى متعاقب را خارج آكاهى هشيار افراد فعال مى كند

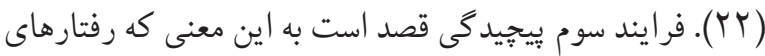

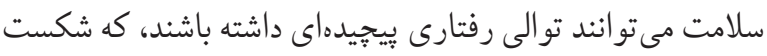

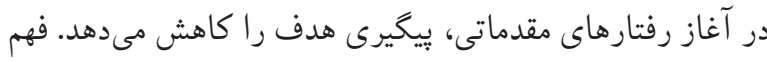

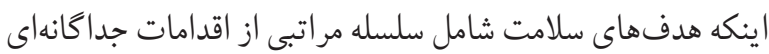

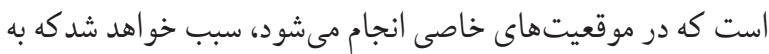
وضوح بفهميم جققدر شناخت وسيلهها (اقدامات) و زمينه (نشانه هاى درونى يا بيرونى) كمك مى كند تا قصد رفتار تحقق بيدا كند، به ويزه

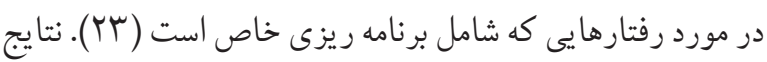

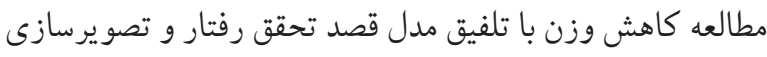

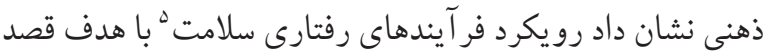
تحقق رفتار در افزايش فعاليت بدنى، تغذيه سالم و يادآورى ديكر اهداف سلامتى اثر بخش بود (YF).

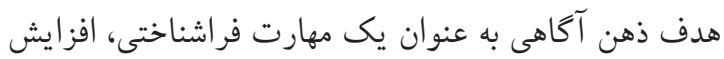

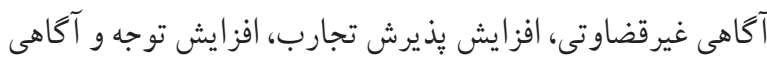

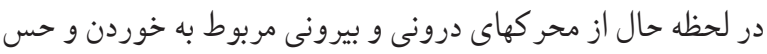
حركت براى افزايش فعاليت بدنى است. شواهد برخى مطالعات

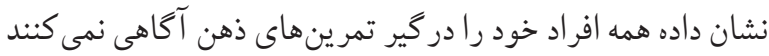

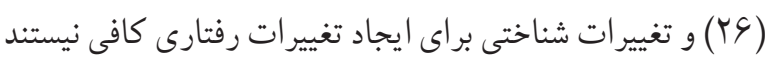

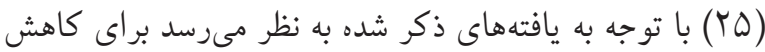

5. Health Action Process Approach
طيف گستردهاى از شيوههاى مراقبه ذهن آكاهى، شيوه هاى خوردن

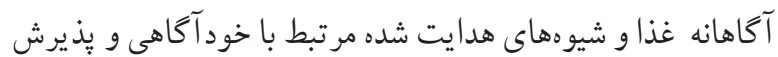
خود را در برمى گيرد. اين شيوه درمانى با يكيارجه كردن درمان

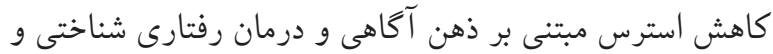

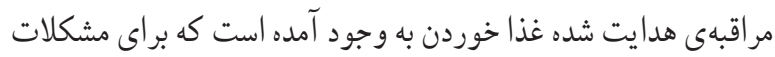

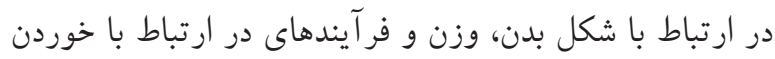
همجِون اشتها و سيرى حسى (SSS) ' و مانند آنها مورداستفاده

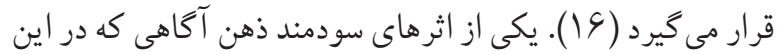
مداخله مدنظر است، بالا بردن توان افراد براى خود تنظيمى است.

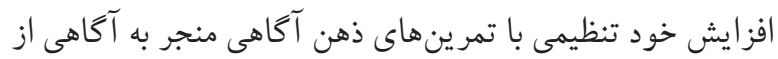

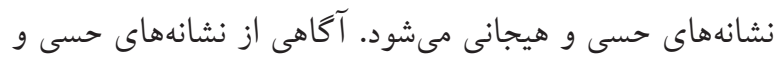

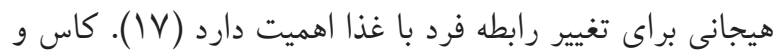

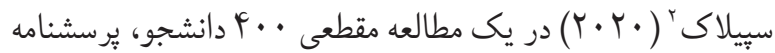

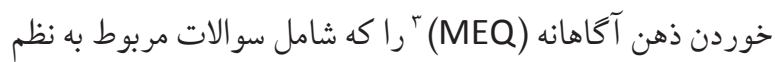

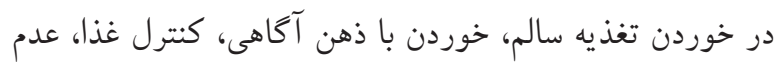
بازدارى و غيره بود تكميل كردند. نتايج نشان داد كه آموزش

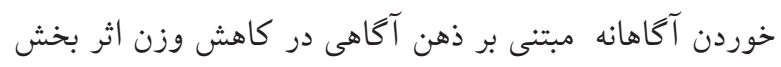

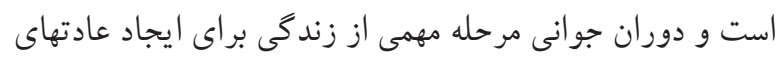

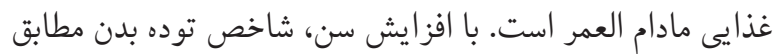
انتظار افزايش مىيابد، اين مىتواند منجر به اختلال در كيفيت

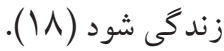

مدل قصد تحقق رفتار ثراهبردى ارادى براى ترجمه قصد و

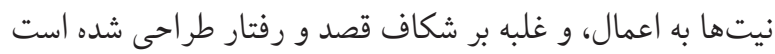
(19). بين قصد هدف و قصد تحقق رفتار تمايز وجود دارد. قصد بـ بهد هدف مربوط به دستيابى به يك هدف (يعنى قصد رسيدن به X) در حاليكه قصد تحقق رفتار، مربوط به برنامه ريزى در مورد اينكه قصد هدف، كى، كجا، و جگونه تبديل به رفتار مىشود (يعنى (اهنكام

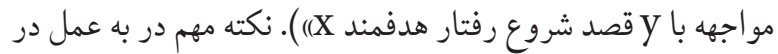

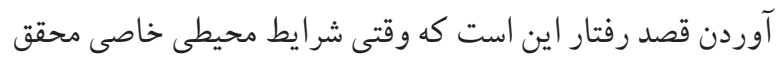

1. Sensory-specific Satiation and Satiety 2. Kose \& Ciplak

3. Mindful Eating Questioners

4. Implementation intentions 
روش اجرا: ملاكهاى ورودّ به ثُزوهش، شاخص توده بدنى

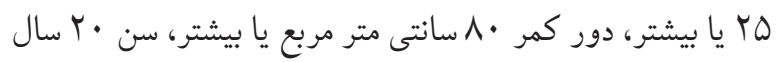

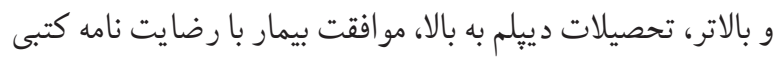

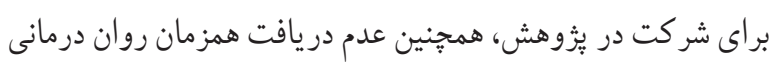

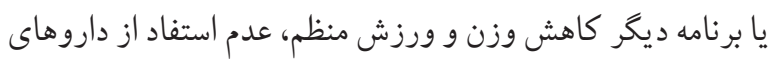

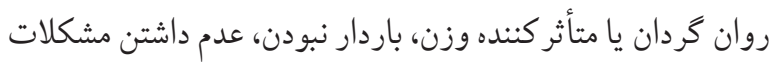

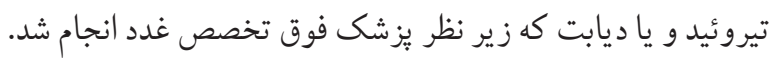
ملاك هاى خروج"،بيش از سه جلسه غيبت در جلسات آموزشى.

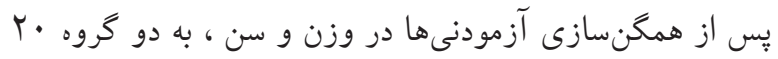

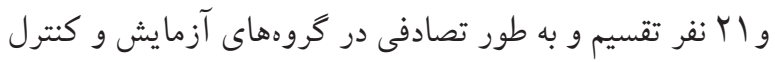

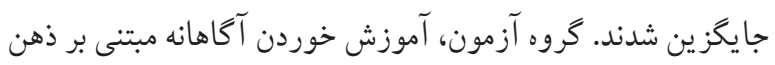

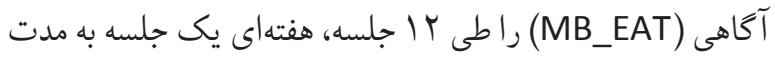

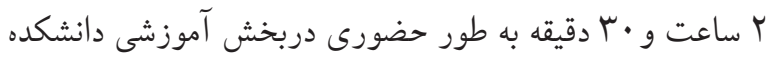

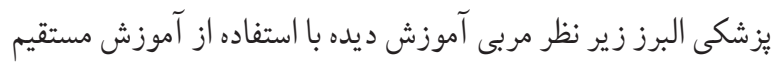
تمرينهاى ذهن آكاهى در خوردن آكاهانه به شكل مشار كت فعال

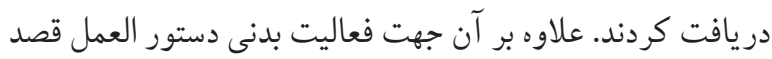

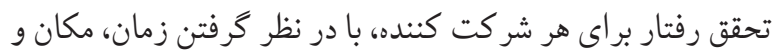
جخونكى انجام فعاليت توسط يك قرار داد رفتارى تنظيم و ميزان

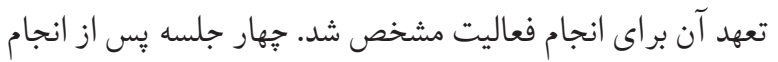
مداخله به طور حضورى به دليل شيوع همه گيرى كوويد - 19 و و

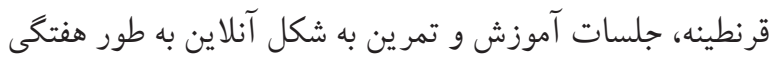

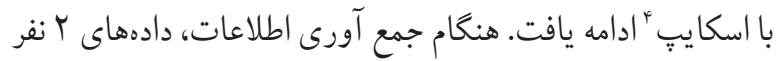

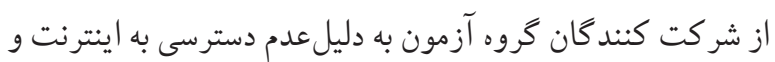
يا مشكلاتى در نصب اسكايب كه از ادامه جلسات باز مانده بودند

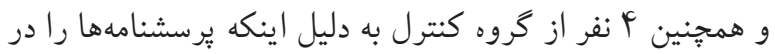

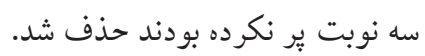
ابزار سنجش سل الف)ارزيابى شاخص هاى زيستى: براى اندازه خيرى وزن از ترازوى

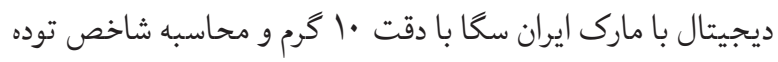

2. Inclusion criteria

3. Exclusion criteria

4. .Skype
وزن تغييرات شناختى با افزايش دانش و آكاهى و انجام تمر ينات

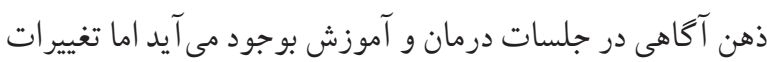
رفتارى مانند ورزش نياز به برنامه ريزى، در نظر كرفتن شرايط

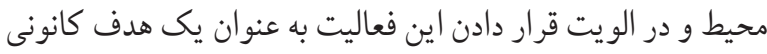

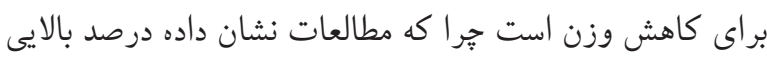
از افراد ورزش نكردن را نداشتن وقت و مشغله زياد ذكر مى كنند (YV)

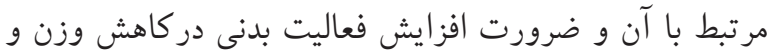
سلامتى، درمطالعه حاضر سعى شده تا با تلفيق خوردن آكاهانه

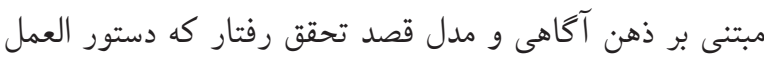

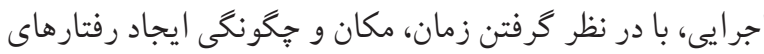

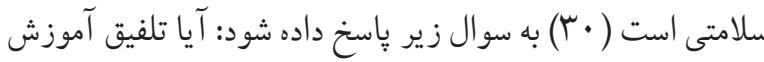
خوردن آكاهانه مبتنى بر ذهن آكاهى (MB_EAT) و مدل قصد تحقق رفتار بر شاخص توده بدن، دور كمر، خوردن ذهن آناهانه آنهانه

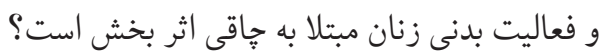
مواد و ورش هاد روش يُزوهش جامعه و نمونه گيرى: مطالعه حاضر از نوع نيمه

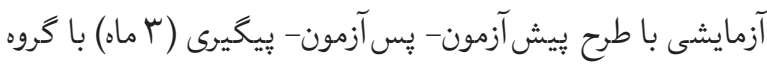

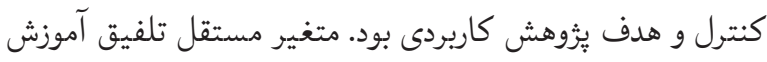

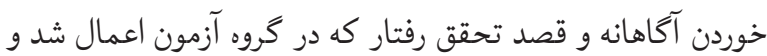
دركروه كنترل مداخلهاى انجام نشد. متغيرهاى وابسته شاخص توده بدنى، دوركمر، خوردن ذهن آكاهانه و فعاليت بدنى بودند. جامعندي

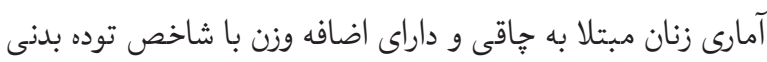

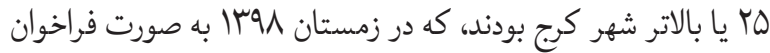
در شبكههاى مجازى به مدت ب ماه براى شركت در يُزوهش از آنها

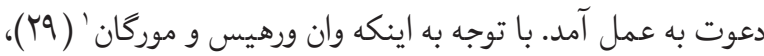

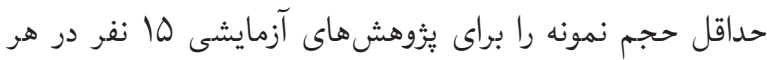

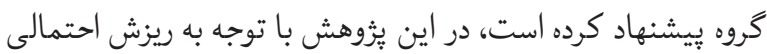

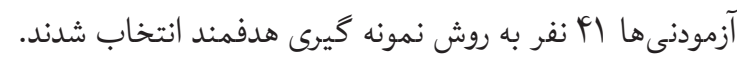

1. Van Voorhis CRW, Morgan BL 
ندرت؛ گاهى اوقات؛ اغلب و معمولاً/ هميشه مورد ارزيابى قرار مى

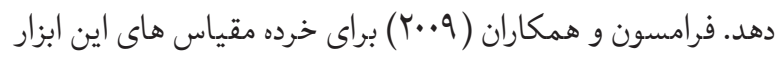

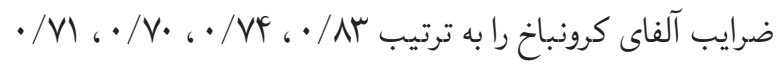

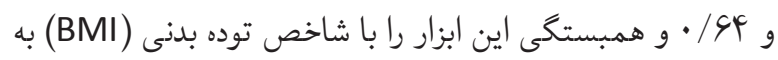

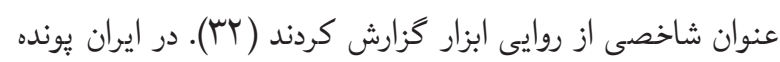

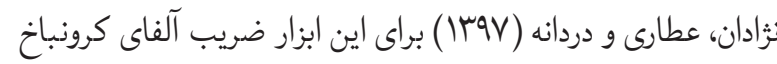

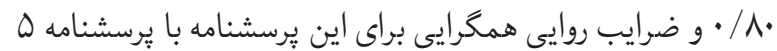

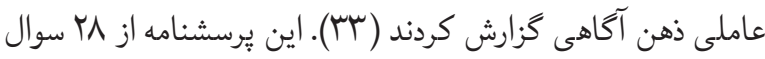

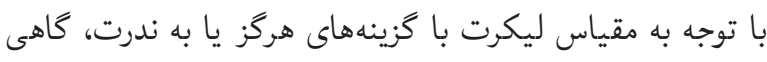

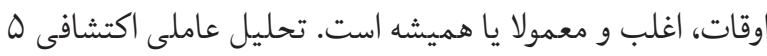

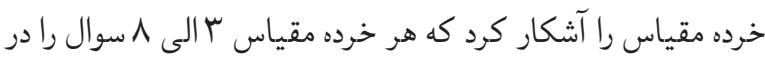

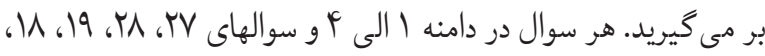

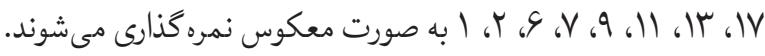

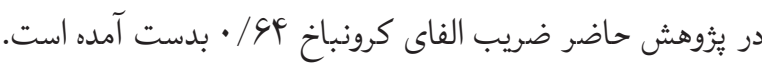
آموزش خوردن آكاهانه مبتنيى بر ذهن آكاهيى (MB_EAT) رويكردى در زمينه درمان جاقى است كه اصول ذهن آكاهى، رابطه

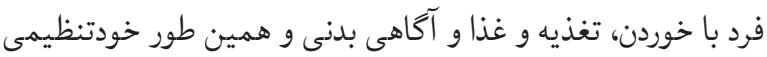

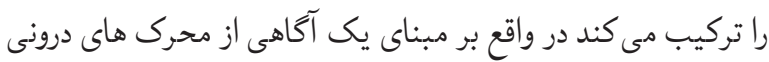

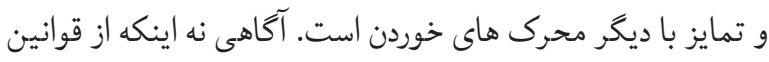
و دستور العملهاى خارجى به طور دقيق پييروى كردن بلكه متصل

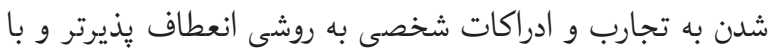

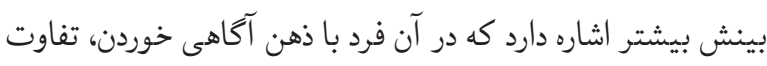

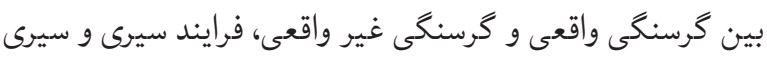

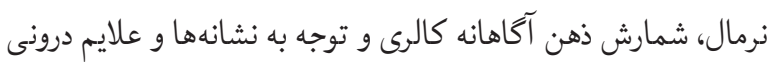

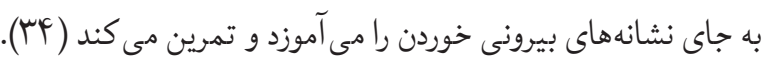

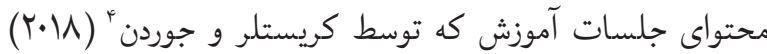
تدوين شده در جدول شماره آ آمده است.

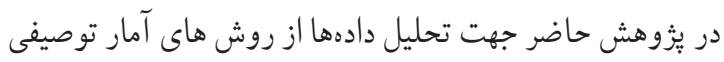

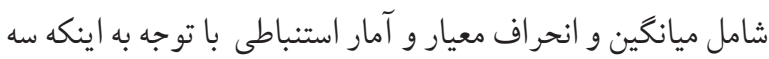
مرحله يِيش آزمون، پِ آزمون و يِيخيرى بوده و همه دادهها نرمال
بدنى (BMI) از تقسيم وزن به كيلو گرم بر مجذور قد به متر (^)، دور كمر در باركترين ناحيه با متر نوارى (دقت ه / • سانتى متر)

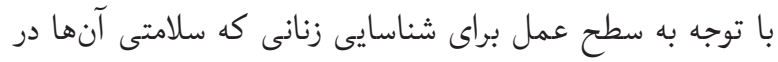
خطراست دور كمر بزرگتر يا مساوى •^مر نظر گرفته مى شود (·ץ).

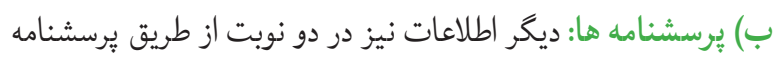
به روش خود گزارش دهى در دو بخش تنظيم شد. بخش اول: جهت سنجش اطلاعات دموكرافيك ( سن، جنسيت، تحصيلات،وزن و...) و سابقه بيمارى هاى متاثر كننده وزن(ديابت،

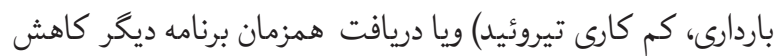
وزن شركت كننده ها در يُّوهش بود (سا سوال) و اطلاعات بِايه در مورد فعاليت بدنى در دو روزكارى و يك روز تعطيل كه توسط آزمودنى ها با اطلاع قبلى ثبت و در در اختيار يُزوهشكر قرار كرفت.

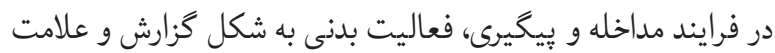
زدن در جك ليست محقق ساخته در يك مقياس ليكرت ( با دامنه

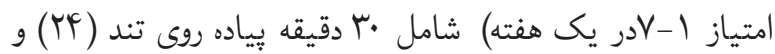

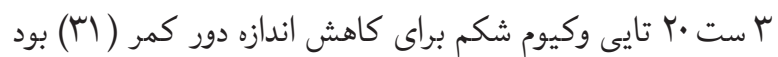

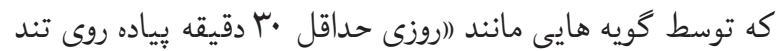
دارم) سنجيده شد. اعتبار علمى ابزارها از طريق سنجش روايى

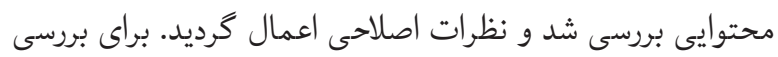

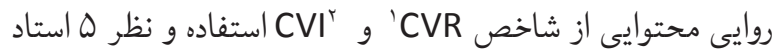
روانشناس در حوزه سلامت و هيات علمى دانشخاه استفاده شد كه

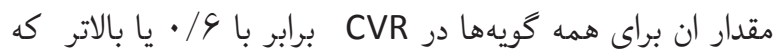

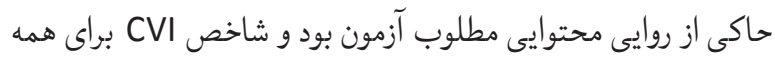

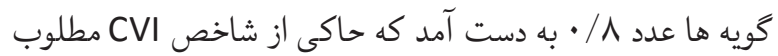
با توجه به نقاط برش اين شاخص براى اين ابزار بود.

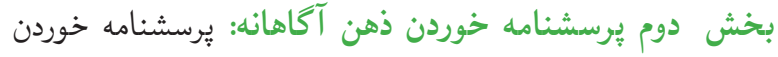

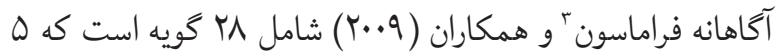

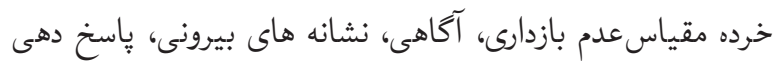

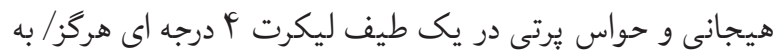

1. Content Validity Ratio

2. Content Validity Index (CVI)

3. Framson 
جدول ا. طرح كلى آموزش خوردن آكًاهانه مبتنى برذهن اكاهى كريستلر و جوردن (1 | • r)

\begin{tabular}{|c|c|c|}
\hline ابزار آموزش & محتواى و اهداف جلسات آموزش & جلسه \\
\hline 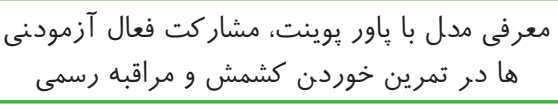 & 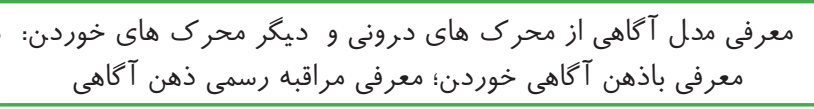 & جلسه | \\
\hline 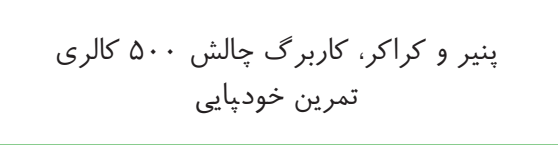 & 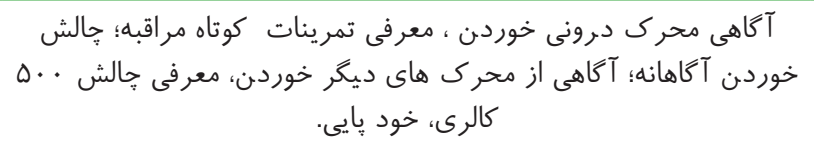 & جلسه r \\
\hline 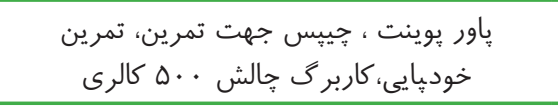 & 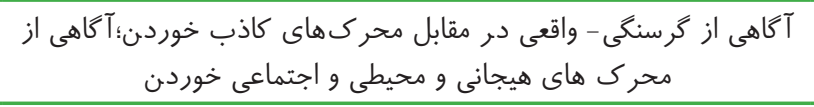 & جلسه بَ \\
\hline تمرين ذهن آكاهانه شكلات يا كوكى شارى & 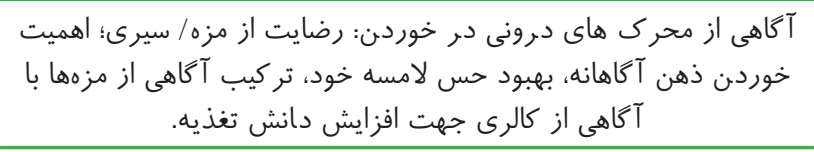 & جلسه F \\
\hline 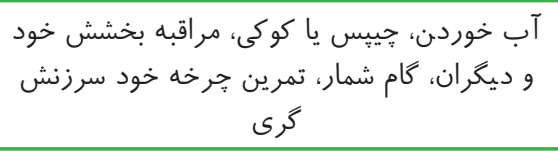 & 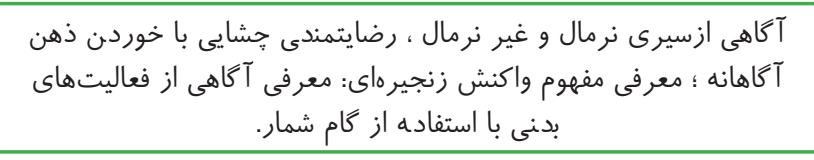 & جلسه ه \\
\hline مر اقبه خوردن با ذهن آكاهى، مقياس سيرى، هرم & انتخاب ذهن اگاهانه غذاها (ميوه وسبزيجات)؛ برآورد نياز به انرزى. & جلسه 9 \\
\hline 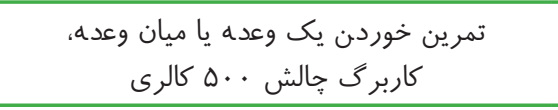 & مقايسه علايم و نشانه هاى واقعى و كاذب در خوردن؛ مرور خالش . & جلسه V \\
\hline تمرين هاى ذهن آكاهانه جهت افزايش فعاليت & خوديايى بدنى و يوكاى نشسته؛ تجديدنظر درمحر ك هاى خوردن؛ افزايش & جلسه 1 \\
\hline 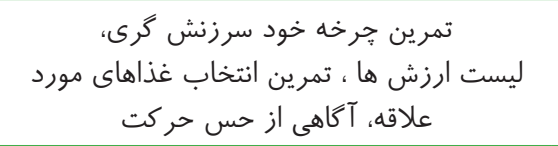 & قطع واكنش زنجيرهاى؛ شناسايى ارزشهاء؛ انتخاب غذاهاى تغور مورد علاقه؛ & جلسه 9 \\
\hline مراقبه، يك ميان وعده به اختيار هر يك از شركت & مراقبه خردمندانه؛ ميان وعده سالم. & جلسه • 1 \\
\hline 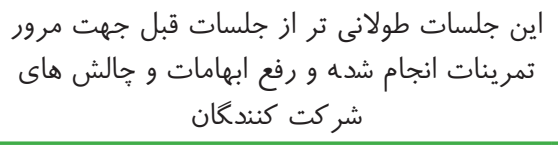 & تمرينات ذهن آكاهى؛ مرورى بر بِيشرفتها؛ مراقبه يذيرش خود؛؛ نغهدارى & جلسه هاى 1 | 1 | \\
\hline
\end{tabular}

و انحراف معيار قد كروه آزمون ه ه

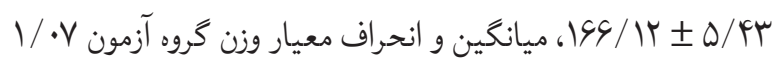
و

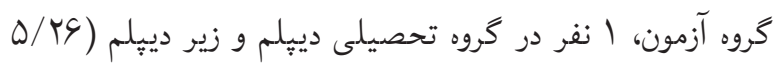

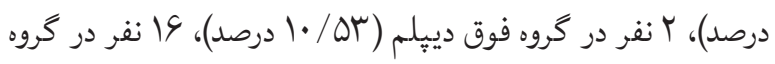

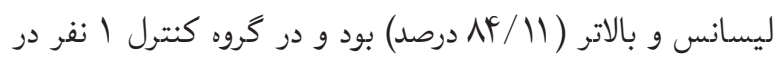

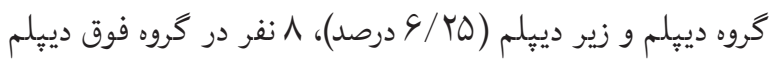

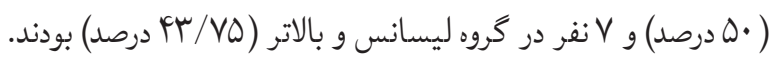

بود از روش تحليل طرح آميخته استفاده شده است. ديكر آزمونهاى

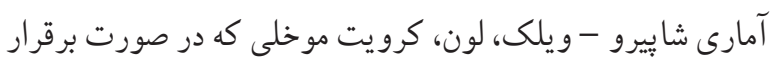

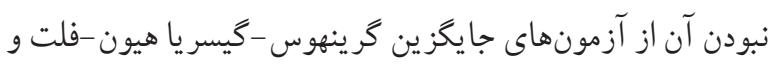

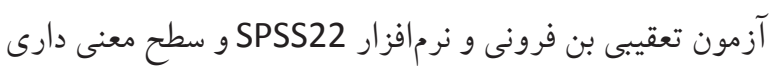

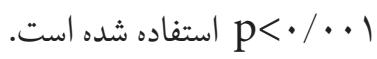

يافته ها نتايج آمار توصيفى نشان داد كه ميانكين و انحراف معيار سنى گروره آزمون 
جدول r. ميانگين و انحراف استاندارد و آماره شاييرو- ويلكز دور كمر و شاخص توده بدنى و فعاليت بدنى

\begin{tabular}{|c|c|c|c|c|c|c|}
\hline سطح معنادارى & شاييرو- ويلكز & 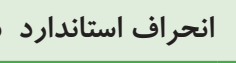 & ميانغين & 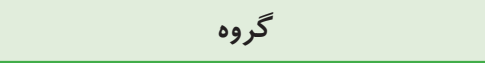 & وضعيت & 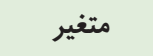 \\
\hline$\cdot / \cdot \Delta r$ & $\cdot / \wedge \Lambda 1$ & $V / \Delta \Delta$ & $1 \cdot / 10$ & تلفيق خوردن آكاهانه با قصد تحقق رفتار & \multirow{2}{*}{ بِيش آزمون } & \multirow{6}{*}{ ل - مور كمر } \\
\hline$\cdot / 9 G 4$ &.$/ 99$ & $\Lambda / F$ & $\Lambda \cdot / V \Delta$ & 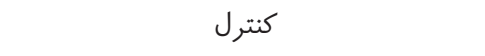 & & \\
\hline.$/ . \Delta \Delta$ & $\cdot /$ AVr & $V / \mu f$ & $V F / 9 \Lambda$ & تلفيق خوردن آكاهانه دبا قصد تحقق رفتار & \multirow{2}{*}{ 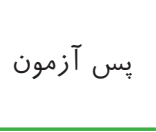 } & \\
\hline$\cdot / \operatorname{AVr}$ &.$/ 9 V r$ & $\wedge / 1$ & $\vee ৭ / \mu v$ & كنترل & & \\
\hline$\cdot / \cdot \Delta F$ & $\cdot / 19$. & $V / \mu \mu$ & $V r / V r$ & تلفيق خوردن آكاهانه با قصد تحقق رفتار & \multirow{2}{*}{ بيغيرى } & \\
\hline$\cdot / \mathrm{s}$ &.$/ 99 V$ & $N / \cdot 9$ & $\Lambda \cdot / F r$ & 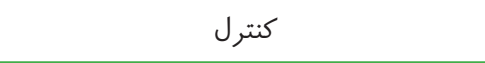 & & \\
\hline /. $/ \Delta r$ & $\cdot / \Lambda \mu$. & $1 / \cdot 0$ & $\mathrm{~V} / / \cdot$ & تلفيق خوردن آكاهانه با قصد تحقق رفتار & \multirow{2}{*}{ 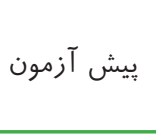 } & \multirow{6}{*}{ شاخص توده } \\
\hline$\cdot / \cdot \Delta$ & $\cdot / \wedge \mid \wedge$ &.$/ 99$ & $\mathrm{~V} / \cdot \cdot$ & 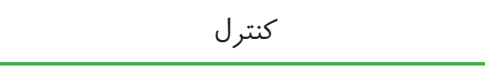 & & \\
\hline$\cdot / \cdot \Delta \cdot$ & $\cdot / \wedge \wedge \Delta$ & $\cdot / 4$ & $\mathrm{VI/ \Delta V}$ & تلفيق خوردن آكاهانه با قصد تحقق رفتار & \multirow{2}{*}{ 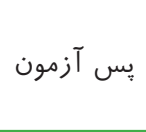 } & \\
\hline.$/ .01$ & $\cdot /$ AVS & $\cdot / 19$ & $\mathrm{~V} / / \cdot$ & كنترل & & \\
\hline$\cdot / \cdot \Delta F$ & 吾 &.$/ 9 \vee$ & sq/VA & تلفيق خوردن آكاهانه با قصد تحقق رفتار & \multirow{2}{*}{ ييغيرى } & \\
\hline$\cdot / r \mid r$ & .1948 & $1 / 19$ & $V V / 1 \Lambda$ & كنترل & & \\
\hline$\cdot / \cdot \Delta \wedge$ & $\cdot / 9 \cdot 4$ & $r / 1 \Lambda$ & rN/9I & تلفيق خوردن آكاهانه با قصد تحقق رفتار & \multirow{2}{*}{ پِيش آزمون } & \multirow{6}{*}{ 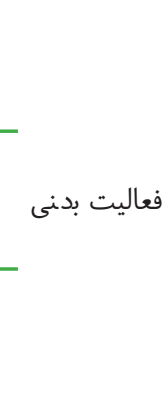 } \\
\hline$\cdot / r \wedge 9$ &.$/ 940$ & $r / 90$ & $r q / .9$ & كنترل & & \\
\hline 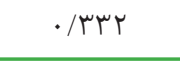 &.$/ 948$ & $r / \Lambda F$ & $r F / .9$ & تلفيق خوردن آكاهانه با قصد تحقق رفتار & \multirow{2}{*}{ 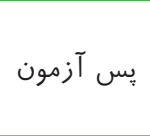 } & \\
\hline.$/ 119$ &.$/ 91$ & $r / \wedge F$ & $r q / .9$ & كنترل & & \\
\hline . & . /А१४ & $r / \Delta r$ & $r r / s 0$ & تلفيق خوردن آكاهانه با قصد تحقق رفتار & \multirow{2}{*}{ 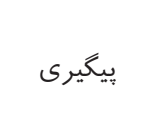 } & \\
\hline .1 .91 & $\cdot / 9 \cdot r$ & $r / \wedge \Delta$ & $r q / . r$ & كنترل & & \\
\hline
\end{tabular}

هاى عدم بازدارى، آكاهى، باسخ دهى هيجانى بزرگ تر از VD/ • و براى

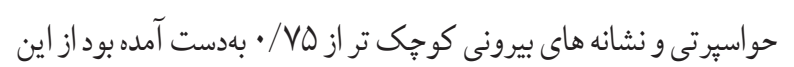

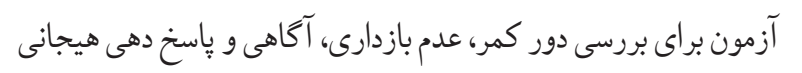

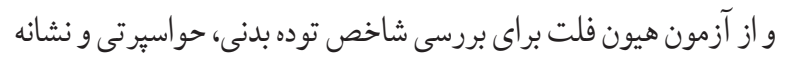
هاى بيرونى استفاده شد.

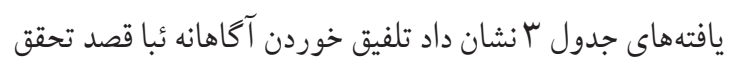

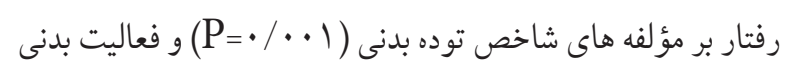

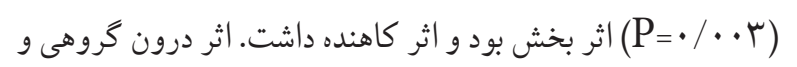

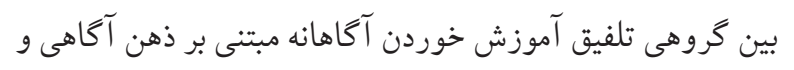
قصد تحقق رفتار بر شاخص توده بدنى و فعاليت بدنى معنى دار بود.
يافتههاى جدول ب نشان مى دهد توزيع دادهها به استثناى موارد مشخص

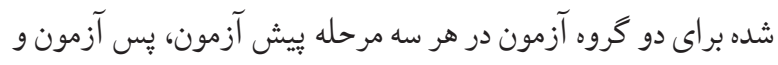

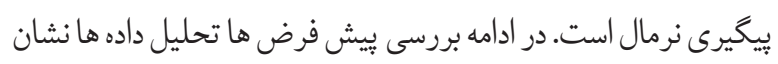

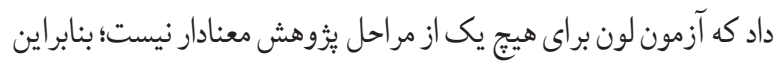

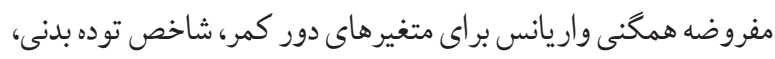

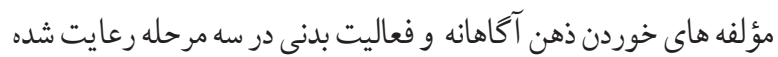

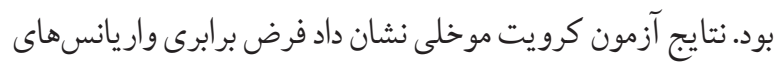

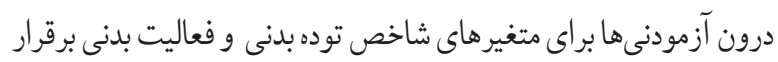
بود اما براى متغير دور كمر و مولفه هاى خوردن ذهن آكاهانه برقرار نبود. با توجه به اين كه مقدار إِسيلون كرينهوس -كيسر ' براى دور كمر و مولفه دونه 
جدول س. نتايج تحليل طرح آميخته در تبيين اثر متغيرهاى مستقل بر دور كمر، شاخص توده بدنى وفعاليت بدنى

\begin{tabular}{|c|c|c|c|c|c|c|}
\hline$\eta r$ & مقدار احتمال & $\mathbf{F}$ & ميانكين مجذورات & درجه آزادى & مجذورات & مؤلفهها \\
\hline$\cdot / \cdot V^{F}$ &.$/ 114$ & $r / \xi \mu$ & FIO/VV & 1 & FIO/VV & اثر گروه \\
\hline$\cdot / 9 V 9$ & $\cdot / \cdot 1$ & sq/AV & $r F V / . r$ & $1 / \cdot 1$ & $r s V / 11$ & اثر زمان \\
\hline.$/ \Delta V Y$ &.$/ \cdots 1$ & $p q / \cdot F$ & $|\Delta \Delta / V|$ & $1 / \cdot 1$ & 1SN/\% & اثر متقابل \\
\hline ./1८9F &.$/ .1$ & TVN/qF & FVO/VV & 1 & FVO/VV & اثر كروه \\
\hline$\cdot / A V F$ &.$/ \cdot 1$ & rTN/Vq & $11 V / 90$ & r & $r \tilde{L} / \mu$ & اثر زمان \\
\hline · /A^r &.$/ \cdot 1$ & $r F V / 9 D$ & $\mid r V / F r$ & $r$ & TOF/AD & اثر متقابل \\
\hline$\cdot / r q$. &.$/ .1$ & $\mid r / 4 s$ & TrT/VD & 1 & TrT/VD & اثر كروه \\
\hline - /AFA &.$/ \ldots 1$ & $\mid \wedge r / 4 q$ & $11 / 4 q$ & $1 / 91$ & IFA/MA & فعاليت بدنى \\
\hline ./AFV &.$/ . .1$ & $1 \wedge \mu / 19$ & $M N /{ }^{\prime} F$ & $1 / 91$ & $I F N / G F$ & اثر متقابل \\
\hline
\end{tabular}

جدول عا. نتايج آزمون تعقيبى بن فرونى براى مقايسههاى زوجى اثر زمان ها

\begin{tabular}{|c|c|c|c|c|c|}
\hline مقدار احتمال & خطاى معيار & تفاوت ميانگين & & تفاوت زمانها & \\
\hline$\cdot / \cdot 1$ &.$/ 499$ & $r / \notin r$ & پس آزمون & \multirow{2}{*}{ يِش آزمون } & \multirow{6}{*}{ 2) } \\
\hline.$/ \cdots 1$ & $\cdot / \boldsymbol{F} \cdot r$ & r/ץ & پيخيرى & & \\
\hline.$/ \ldots 1$ &.$/ 499$ & $-r / F r$ & يِشآزمون & \multirow{2}{*}{ ֶس آزمون } & \\
\hline $1 / \ldots$ &.$/ .94$ & $-\cdot / \cdot \Delta \Lambda$ & ييخيرى & & \\
\hline.$/ \cdot 1$ & $\cdot / \boldsymbol{q} \cdot r$ & - & يِيشآزمون & \multirow{2}{*}{ پيخيرى } & \\
\hline $1 / \ldots$ &.$/ .94$ &.$/ \cdot \Delta \lambda$ & ֵֶسآزمون & & \\
\hline.$/ . .1$ &.$/ 100$ & $r / F 1$ & ״س آزمون & \multirow{2}{*}{ يِش آزمون } & \multirow{6}{*}{ 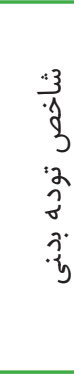 } \\
\hline.$/ \cdot 1$ & $\cdot / 1 \wedge F$ & $r / s q$ & يِيگيرى & & \\
\hline.$/ \cdot 1$ &.$/ 100$ & $-Y / F 1$ & ييش آزمون & \multirow{2}{*}{ ֶس آزمون } & \\
\hline.$/ 1 \mu \wedge$ &.$/ 11 r$ & . & پيخيرى & & \\
\hline.$/ .1$ & $\cdot / 1 \wedge F$ & $-r / G \varphi$ & ي يِش آزمون & \multirow{2}{*}{ يِيخيرى } & \\
\hline . / r & $\cdot / 11 r$ & - & يسآزمون & & \\
\hline.$/ .1$ & .1 .91 & $-1 / V \wedge$ & يس آزمون & \multirow{2}{*}{ يِش آزمون } & \multirow{6}{*}{$\begin{array}{l}3 \\
3 \\
3 \\
3 \\
y \\
3 \\
y\end{array}$} \\
\hline.$/ \cdots 1$ &.$/ 1 Y s$ & $-1 / \wedge V$ & يِيخيرى & & \\
\hline $.1 \cdot 1$ & .1 .91 & I/VA & ييش آزمون & \multirow{2}{*}{ ֶِ آزمون } & \\
\hline $1 / \cdot$ &.$/ .9 \mathrm{~V}$ &.$- / .9$. & يِيخيرى & & \\
\hline.$/ .1$ &.$/ 1{ }^{2}$ & I/AV & ييش آزمون & \multirow{2}{*}{ بيخيرى } & \\
\hline $1 / \cdot$ &.$/ .9 V$ &.$/ .9$ & يس آزمون & & \\
\hline
\end{tabular}

يافتهاى بن فرونى( جدول F) نشان مى دهد بين ميانكين هاى تلفيق آموزش خوردن آكاهانه مبتنى بر ذهن آكاهى و مدل قصد تحقق

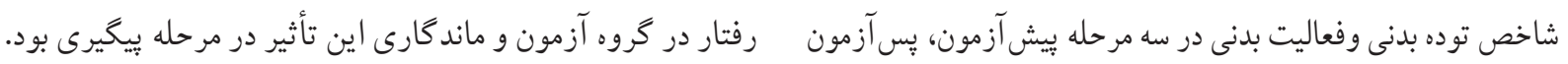

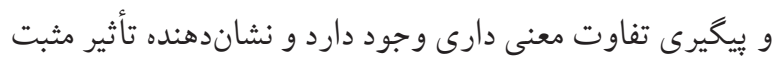


جدول ه. ميانگين و انحراف استاندارد و آماره شاييرو- ويلكز مؤلفهاى خوردن آ كاهانه

\begin{tabular}{|c|c|c|c|c|c|c|}
\hline سطح معنادارى & شاييرو- ويلكز & استاندارد افحراف & 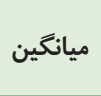 & 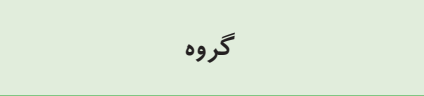 & وضعيت & 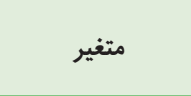 \\
\hline$\cdot / s q V$ &.$/ 9 s 4$ & $\cdot / 9 \wedge F$ & $V \cdot / \mu l$ & تلفيق خوردن آكاهانه با قصد تحقق رفتار & 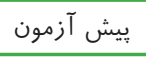 & خوردن آكاهانه \\
\hline$\cdot /$ r &.$/ 9 F r$ & $\cdot|s \mu|$ & $v \cdot / 1 r$ & 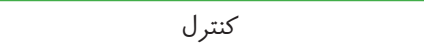 & & \\
\hline.$/ I F F$ &.$/ 948$ & $\cdot / \Lambda \cdot V$ & $\Delta r / \Delta r$ & تلفيق خوردن آكاهانه با قصد تحقق رفتار & 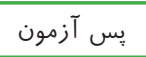 & \\
\hline$\cdot / 0 \cdot r$ &.$/ 901$ &.$/ 49 \mathrm{~V}$ & $v \cdot / \cdot 4$ & كنترل & & \\
\hline.$/ 94 V$ &.$/ 91$ & $\cdot / \& \vee \mu$ & $\Delta r / r l$ & تلفيق خوردن آكاهانه با قصد تحقق رفتار & 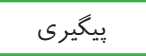 & \\
\hline$\cdot / r \backslash \Lambda$ &.$/ 9 r V$ &.$/ 41 r$ & $\vee \cdot / \cdot$ & كنترل & & \\
\hline - /vor &.$/ 999$ & $r / l f$ & $r r / F r$ & تلفيق خوردن آكاهانه با قصد تحقق رفتار & \multirow{2}{*}{ 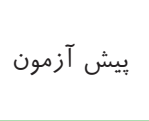 } & \multirow{6}{*}{ 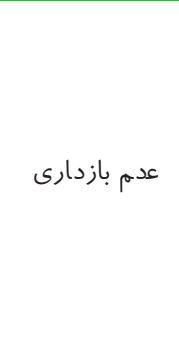 } \\
\hline$\cdot / r S V$ & 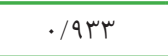 & $1 / \wedge 9$ & $r I / F r$ & كنترل & & \\
\hline.$/ 199$ & . & $1 / 9 \wedge$ & $|\Delta / r|$ & تلفيق خوردن آكاهانه با قصد تحقق رفتار & \multirow{2}{*}{ 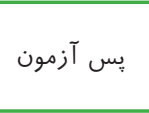 } & \\
\hline$\cdot / \wedge \vee \Delta$ &.$/ 9 V r$ & $1 / v \wedge$ & $r \mid / \Delta Q$ & كنترل & & \\
\hline$\cdot / \cdot \Delta \Lambda$ & $\cdot / \wedge \Delta \Delta$ & $1 / 41$ & $10 / 1$ & تلفيق خوردن آكاهانه با قصد تحقق رفتار & \multirow{2}{*}{ 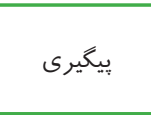 } & \\
\hline$\cdot / r \cdot V$ &.$/ 948$ & $1 / 0$ & rI/OS & كنتر ل & & \\
\hline$\cdot / \cdot V 4$ & .1911 & $1 / 1 F$ & $9 / 1$ & تلفيق خوردن آكاهانه با قصد تحقق رفتار & \multirow{2}{*}{ ي بيش آزمون } & \multirow{6}{*}{ آكاهى } \\
\hline.$/ \cdot 4 \Delta$ & $\cdot / \Lambda \Lambda F$ & $1 / \cdots$ & $q / r \Delta$ & كنترل & & \\
\hline$\cdot / \cdot 01$ & $\cdot / 9 \cdot r$ &.$/ 91$ & $|\varepsilon / r|$ & تلفيق خوردن آكاهانه با قصد تحقق رفتار & \multirow{2}{*}{ 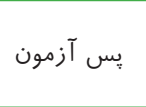 } & \\
\hline.$/ .01$ & $\cdot / 9 \cdot r$ & $1 / \cdot r$ & $9 / 1 r$ & كنترل & & \\
\hline$\cdot / \cdot \Delta V$ & $\cdot / 9 \cdot 0$ &.$/ 97$ & $\mid 9 / \ldots$ & تلفيق خوردن آكاهانه با قصد تحقق رفتار & \multirow{2}{*}{ يِيخيرى } & \\
\hline$\cdot / \cdot \Delta \varphi$ & $\cdot / 9 \cdot 1$ &.$/ 99$ & N/9T & كنترل & & \\
\hline$\cdot /$ /r人 &.$/ 940$ & 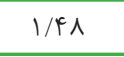 & $10 / T^{4}$ & تلفيق خوردن آكاهانه با قصد تحقق رفتار & \multirow{2}{*}{ 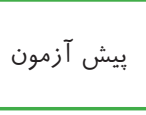 } & \multirow{6}{*}{ 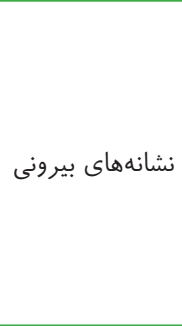 } \\
\hline$\cdot / \cdot \Delta F$ & $\cdot / 9 \cdot V$ & $1 / r$ & $10 / \mu v$ & كنتر ل & & \\
\hline$\cdot / \cdot \Delta$ & $\cdot / 9 \cdot 1$ & $1 / \mu$ & $1 \cdot /$ He $^{-1}$ & تلفيق خوردن آكاهانه با قصد تحقق رفتار & \multirow{2}{*}{ 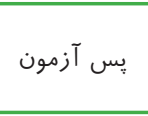 } & \\
\hline$\cdot / \cdot r \Delta$ & $\cdot / \wedge \vee V$ & $1 / \mu F$ & $10 / r \Delta$ & كنتر ل & & \\
\hline$\cdot / \cdot \Delta 1$ & $\cdot / 9 \cdot r$ &.$/ 99$ & $1 \cdot / \Delta r$ & تلفيق خوردن آكاهانه با قصد تحقق رفتار & \multirow{2}{*}{ بيڤيرى } & \\
\hline.$/ \cdot p q$ & $\cdot / \wedge \wedge \mu$ & $1 / \mathbb{k}$ & $10 / \mu V$ & كنترل & & \\
\hline$\cdot /$ / $\wedge 9$ &.$/ 90$ & $1 / \Delta V$ & $1 \% / r s$ & تلفيق خوردن آكاهانه با قصد تحقق رفتار & \multirow{2}{*}{ 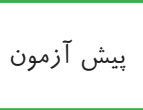 } & \multirow{6}{*}{ ل عِاسخ دهى هيجانى } \\
\hline.$/ 1 F \Delta$ & .1919 & $1 / \pi s$ & $1 r / s r$ & كنتر & & \\
\hline$\cdot / 1 \cdot r$ &.$/ 91 \mathrm{~V}$ & $1 / 1$ & $\mathrm{~V} / \cdots$ & تلفيق خوردن آكاهانه با قصد تحقق رفتار & \multirow{2}{*}{ 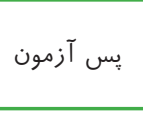 } & \\
\hline$\cdot / \cdot \mu \cdot$ & $\cdot / \Lambda V^{\mu}$ & $1 / \mu$ & $\mid r / 4 \Lambda$ & كنتر ل & & \\
\hline.$/ 1 F \wedge$ &.$/ 945$ & $1 / 1$ & $\mathrm{~V} / \mathrm{l}$ & تلفيق خوردن آكاهانه با قصد تحقق رفتار & \multirow{2}{*}{ ييگيرى } & \\
\hline$\cdot / F \uparrow \wedge$ &.$/ 9 F V$ & $1 / r \Delta$ & $\mid r / 9 \Lambda$ & كنتر ل & & \\
\hline$\cdot / \cdot \Delta \Delta$ & $\cdot / 9 \cdot r$ & $1 / 19$ & $1 \cdot / 10$ & تلفيق خوردن آكاهانه با قصد تحقق رفتار & \multirow{2}{*}{ 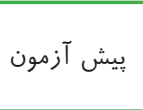 } & \multirow{6}{*}{ حواسِرتى } \\
\hline$\cdot / \cdot \Delta$ & $\cdot / 9 \cdot r$ & $1 / 10$ & $1 \cdot / 4 r$ & كنترل & & \\
\hline$\cdot / \cdot \Delta \varphi$ & $\cdot / 9 \cdot 0$ & $1 / 1 F$ & $r / v r$ & تلفيق خوردن آكاهانه با قصد تحقق رفتار & \multirow{2}{*}{ 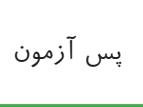 } & \\
\hline$\cdot / \cdot \Delta$ & $\cdot / 9 \cdot r$ & $1 / 10$ & $1 \cdot / 4 r$ & كنترل & & \\
\hline$\cdot / \cdot \Delta \Lambda$ & $\cdot 19 \cdot 9$ & $1 / 1 V$ & $r / F V$ & تلفيق خوردن آكاهانه با قصد تحقق رفتار & \multirow{2}{*}{ ي ي تيكيرى } & \\
\hline.$/ \cdot 0$ & $\cdot / 9 \cdot r$ & $1 / 10$ & $1 \cdot / 4 \mu$ & كنتر ل & & \\
\hline
\end{tabular}




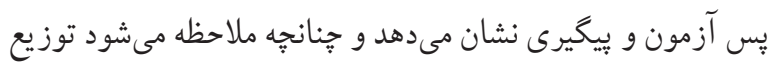

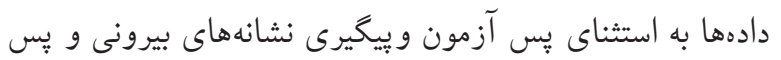
آزمون باسخدهى هيجانى در گروه كنترل نرمال بودند.
جدول ه ميانخين، انحراف استاندارد و آماره شاييرو -ويلك

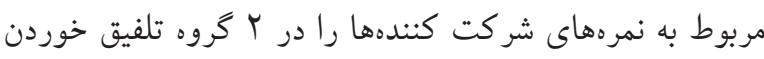

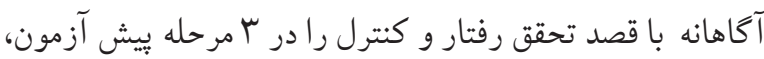

جدول \&. نتايج تحليل طرح آميخته در تبيين اثر متغير هاى مستقل بر مؤلفه هاى خوردن آكَاهانه

\begin{tabular}{|c|c|c|c|c|c|c|c|}
\hline$\eta r$ & مقدار احتمال & $\mathbf{F}$ & ميانگين مجذورات & درجه آزادى & مجذورات مجموع & & مؤلفهها \\
\hline.$/ 911$ & $\cdot / \cdot 1$ & $1 \Delta r / \Delta \Delta$ & rIVA/Vr & 1 & rIVN/VT & اثر گروه & خوردن ذهن آكاهانه \\
\hline •/Arr & $\cdot / \cdot \cdot 1$ & rVs/r. & $\wedge F \mid / \cdot \Lambda$ & $r$ & ISAr/IV & اثر زمان & \\
\hline.$/ 919$ &.$/ \cdot 1$ & rVs/Aq & ATr/DI & $r$ & $\mid G F \Delta / \cdot \mu$ & اثر متقابل & \\
\hline$\cdot|s \mu|$ & $\cdot 1 \cdot \cdot 1$ & $\Delta S / K r$ & $r \cdot r / \Lambda \Lambda$ & 1 & $F \cdot r / M \Lambda$ & اثر گروه & \multirow{3}{*}{ عدم بازدارى } \\
\hline$\cdot / 1 / V$ & $\cdot / \cdot 1$ & $|F V /| r$ & $18 \cdot / 11$ & I/VT & $r 90 / \cdot 9$ & اثر زمان & \\
\hline ./ATV &.$/ \cdot 1$ & $10 V / g r$ & $\mid \wedge r / r \Delta$ & $1 / V \mu$ & ris/Ir & اثر متقابل & \\
\hline$\cdot / \Lambda \Lambda \mu$ &.$/ \cdot 1$ & $r F q / r$. & $\Delta S V / V \mu$ & 1 & $\Delta S V / V^{\mu}$ & اثر گروه & \multirow{3}{*}{ آ آكاهى } \\
\hline.$/ 911$ & $\cdot / \cdots 1$ & $m \in s / l$. & $10 \cdot / 199$ & $1 / V V$ & rबG/9G & اثر زمان & \\
\hline.$/ 9 r T$ & $\cdot / \cdot 1$ & $r q 1 / r$. & $I V \cdot / F F$ & $1 / V V$ & $r \cdot I / V F$ & اثر متقابل & \\
\hline . /GST & $\cdot / \cdots 1$ & $s F / F q$ & $r \wedge \cdot / r \Delta$ & 1 & $r \Lambda \cdot / \Gamma \Delta$ & اثر خروه & \multirow{3}{*}{ نشانههاى بيرونى } \\
\hline$\cdot / \Lambda G F$ & $\cdot / \cdot 1$ & $r \cdot \Lambda / \wedge$. & $V G / F V$ & $1 / 1$. & ITN/IF & اثر زمان & \\
\hline$\cdot / \wedge \Delta \vee$ &.$/ \cdot \cdot 1$ & $19 \mathrm{~V} / \mathrm{VF}$ & $V Y / F r$ & $1 / 1$. & سג/ן & اثر متقابل & \\
\hline.$/ 190$ &.$/ \cdot .1$ & I rN/r. & $\Delta Y q / V I$ & 1 & $\Delta r q / V I$ & اثر گروه & \multirow{3}{*}{ ڤاسخدهى هيجانى } \\
\hline$\cdot / \mathrm{A \Lambda}$ & $\cdot / \cdot 1$ & $|\xi||| f \mid$ & $1 \vee 9 / \cdot r$ & $1 / r s$ & rGS/FV & اثر زمان & \\
\hline$\cdot / 199$ & $\cdot / \cdots 1$ & $1 \Delta \Delta / r q$ & $1 \cdot f / 9 \pi$ & $1 / r G$ & rGr/FA & اثر متقابل & \\
\hline$\cdot / \mathrm{V} r$ & $\cdot / \cdots 1$ & $\| r / \mu \wedge$ & r & 1 & r & اثر گروه & \multirow{3}{*}{ حواسِرتى } \\
\hline.$/ 94$. &.$/ \cdot 1$ & $\Delta I F / \mu F$ & Irr/V. & $1 / f F$ & IVA/Ar & اثر زمان & \\
\hline.$/ 941$ &.$/ \cdot 1$ & $r F Y / \Delta$ & $99 / 11$ & $1 / \mu c$ & $\mid \Lambda V / I \mu$ & اثر متقابل & \\
\hline
\end{tabular}

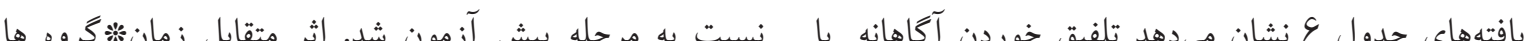

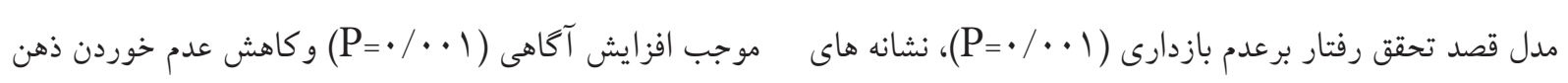

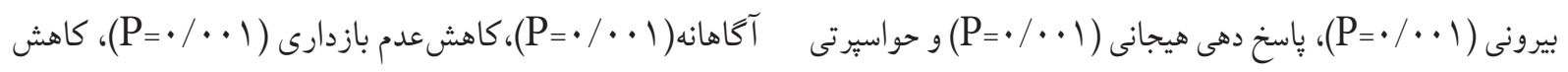

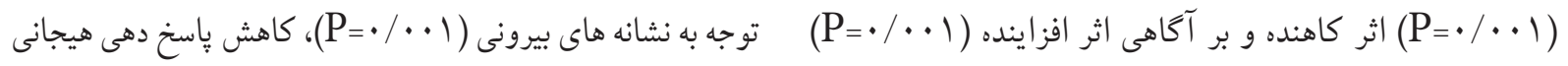

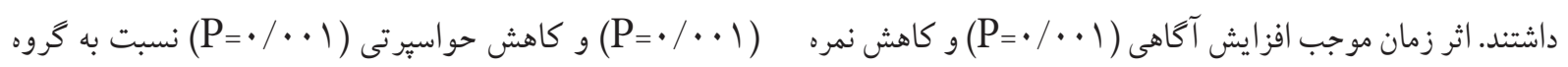

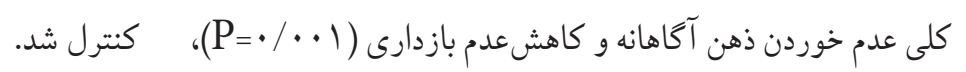

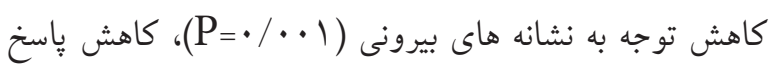

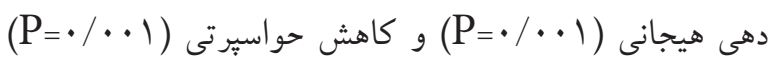


$1 \cdot \Delta$

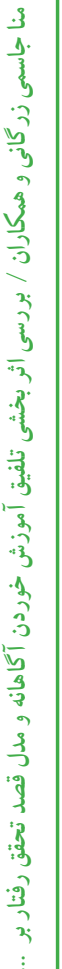

جدول Vانشان مى دهد ميانكين هاى مر حله بيش آزمون با بِ آزمون

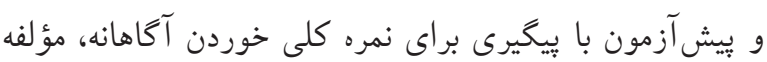

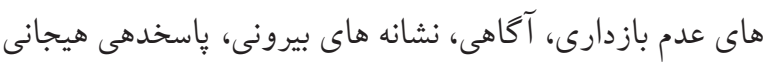

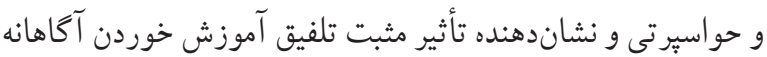

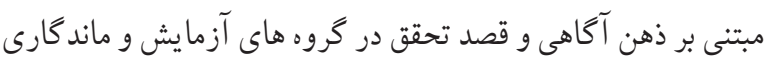
اين تأثير در مرحله ييخيرى بود. بحث

نتايج مطالعه حاضر نشان داد تلفيق خوردن آكاهانه مبتنى بر ذهن آكاهى و مدل قصد تحقق رفتار بر شاخص توده بدنى خوردن

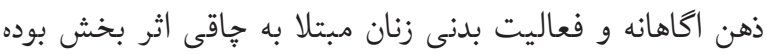

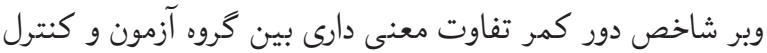

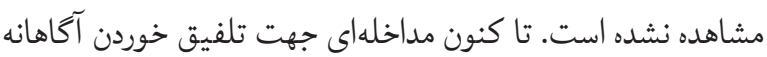
مبتنى بر ذهن آكاهى و مدل قصد تحقق رفتار انجام نشده است

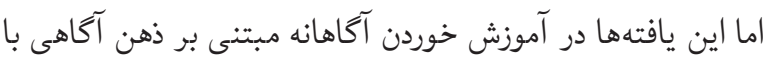
نتايج مطالعات كاس و سييلاك (M) (M )، كريستلر و جوردن (MY)، كاترمن' و همكاران (هاr)در شاخص توده بدن؛ سارتو 'و همكاران

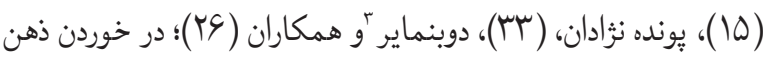
آكاهانه؛ و در فعاليت بدنى، تلفيق قصد تحقق رفتاربا تصويرسازى نواني

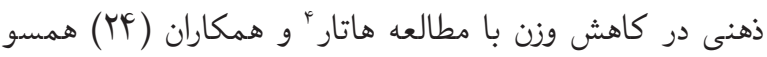

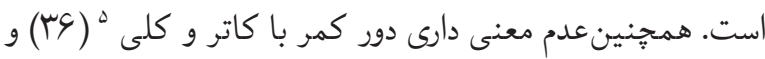
دوبنماير و همكاران (TV) همسو و با مطالعه هاتار و همكاران

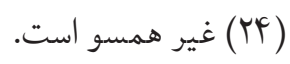

يافته هاى مطالعه حاضر نشان داد اختلاف معنى دارى در وزن و شاخص تودهُ بدنى هر دو گروه آزمون و كنترل قبل و بعد از داز

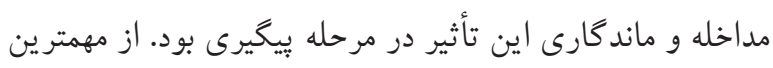

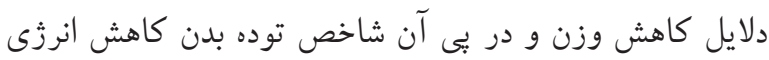

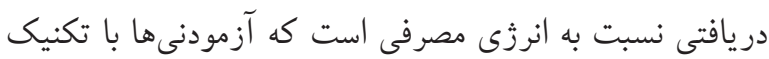

1. Katterman

2. Sarto

3. Daubenmier

4. Hattar

5. Kelly \& Cotter
جدولV. نتايج آزمون تعقيبى بن فرونى براى مقايسههاى زوجى اثر زمان ها

\begin{tabular}{|c|c|c|c|c|c|}
\hline احتمال & خعار & تفاوت ميانكين & \multicolumn{3}{|c|}{ تفاوت زمانها } \\
\hline$\cdot / . .1$ & · & N/Fr & يس آزمون & يِش آزمون & \\
\hline$\cdot / . .1$ & $\cdot / f \cdot F$ & $N / 81$ & ييخيرى & & \\
\hline.$/ .1$ & . /火火ץ & $-N / F r$ & بيش آزمون & سֶس آزمون & $\frac{8}{4}$ \\
\hline $1 / \cdots$ &.$/$ TYS &.$/ 1 \wedge 9$ & ييكيرى & & \\
\hline$\cdot / \cdot 1$ & $\cdot / f \cdot F$ & $-N / 91$ & بيش آزمون & ييكيرى & \\
\hline $1 / \cdots$ & ./TVG & $-\cdot / 1199$ & عِس آزمون & & \\
\hline$\cdot / \cdot 1$ & . IYSG & $r / \Delta F$ & يس آزمون & . $=$ & \\
\hline$\cdot / . .1$ &.$/ T V Y$ & $r / \Delta q$ & يڤيكيرى & צואט & \\
\hline$\cdot / \cdot 1$ & . /YSG & $-r / \Delta r$ & ييش آزمون & (T & \\
\hline $1 / \cdots$ &.$/ I V T$ & $-\cdot / \cdot \Delta r$ & بيكيرى & 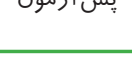 & \\
\hline$\cdot / \cdots 1$ &.$/ r V$. & $-r / \Delta q$ & ييش آزمون & & \\
\hline $1 / \cdots$ &.$/ I V T$ &.$- / . \Delta r$ & يُس آزمون & קֵي & \\
\hline$\cdot / \cdot 1$ &.$/ 194$ & $-r / 4 q$ & يُس آزمون & & \\
\hline$\cdot / . .1$ &.$/ 190$ & $-r / r q$ & ييكيرى & & \\
\hline$\cdot / \cdot 1$ & .1194 & $r / 4 q$ & بيش آزمون & آ & $q_{8}$ \\
\hline . $/ r \mu$. & .11 .9 &.$/ 199$ & ييكيرى & & \\
\hline$\cdot / \cdots 1$ & .1190 & $r / r q$ & يِيش آزمون & 6 & \\
\hline • $/ r \mu$. & .11 .9 &.$- / 199$ & يَس آزمون & "ي & \\
\hline.$/ .1$ &.$/ 149$ & $r / \Delta 1$ & سֶ آزمون & سش آنم & \\
\hline$\cdot / \cdots 1$ &.$/ 100$ & $r / r^{\prime}$ & ييكيرى & 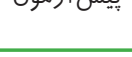 & G. \\
\hline$\cdot / \cdot 1$ &.$/ 149$ & $-r / \Delta 1$ & بيش آزمون & س رآزم & \\
\hline . $/ \Delta F r$ & $\cdot 11 \cdot r$ & $-.|| f \mid$ & يبيكيرى & 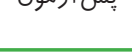 & \\
\hline$\cdot / \cdots 1$ &.$/ 100$ & $-r / r s$ & يِيش آزمون & سكرى & \\
\hline . /DFr & $\cdot / 1 \cdot r$ &.$/|F|$ & يس آزمون & & \\
\hline.$/ .1$ &.$/ 1 \mathrm{VI}$ & $r / 10$ & عِس آزمون & HA & \\
\hline$\cdot / \cdots 1$ &.$/ 198$ & $r / 1$. & ييكيرى & 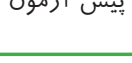 & \\
\hline.$/ . .1$ &.$/ 1 \mathrm{VI}$ & $-r / 10$ & بيش آزمون & يس آزمون & $\xi$ \\
\hline $1 / \cdots$ &.$/ \cdot \wedge r$ & $-\cdot / \cdot \Delta r$ & يِيكيرى & & \\
\hline.$/ . .1$ &.$/ 198$ & $-r / 1$. & بيش آزمون & ييخيرى & \\
\hline $1 / \cdots$ &.$/ \cdot \wedge r$ &.$/ \Delta \mu$ & سֶ آزمون & & \\
\hline$\cdot / . .1$ &.$/ 114$ & $r / \mathrm{VI}$ & يس آزمون & & \\
\hline.$/ . .1$ & .1119 & r/AF & يِيخيرى & צה" & \\
\hline$\cdot / \cdot 1$ &.$/ 11 \pi$ & $-r / V I$ & بيش آزمون & س & G. \\
\hline$\cdot / \cdot 1$ &.$/ . \Delta V$ & . 1 Irr & يِيخيرى & 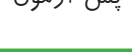 & \\
\hline$\cdot / \cdot \cdot 1$ &.$/ 119$ & $-r / A F$ & يبش آزمون & سك & \\
\hline$\cdot / \cdot 1$ & $\cdot / \cdot \Delta v$ & . Irr & يُس آزمون & 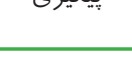 & \\
\hline
\end{tabular}


اين تركيب، به عنوان يافته جديدى است كه در مطالعات بعدى بايد مورد نظر قرار كيرد. در زمينه با ذهن آكاهى خوردن، يافتها مطالعه حود حاضر باعث

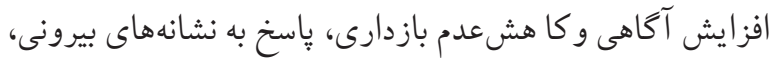

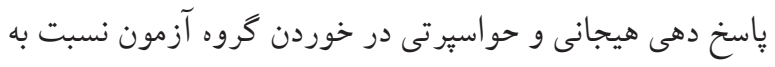

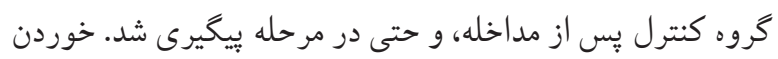

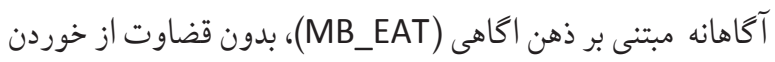
هيجانى وخوردن بر اساس كرسنگى واقعى توصيف مى شود (سT). شواهد مطالعات همسو در آموزش خوردن آكاهانه نشان داد اين

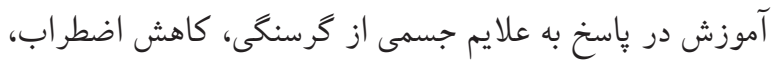

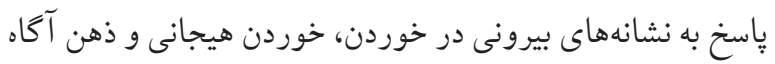

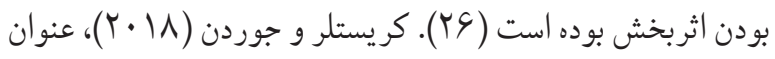
مى كنند افراد در آموزش خوردن آكاهانه مبتنى بر ذهن آكَاهى بهى

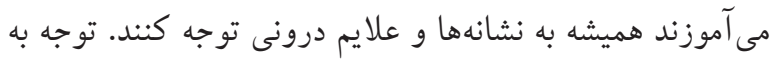

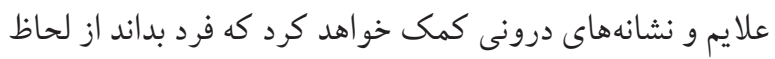
جسمى واقعا گرسنه است يا سير، عطر و طعم غذا براى ادامه دادن به خوردن به اندازه كافى لذت بخش است يا خير همجنين افرد

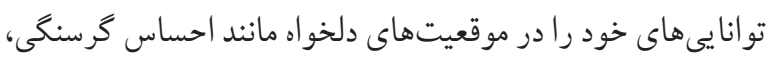

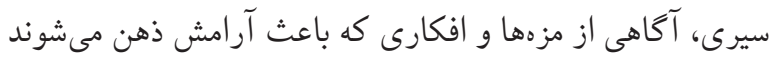

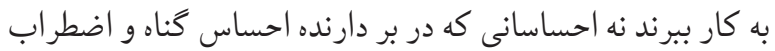
باشند به همين دليل است كه واكنشهاى هيجانى فرد ذهن آكاه

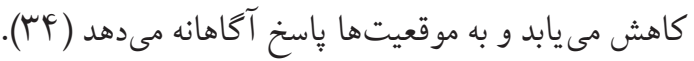

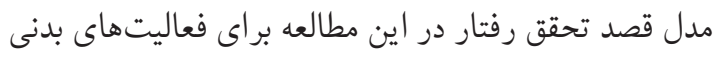

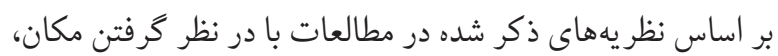

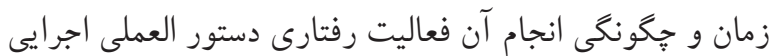

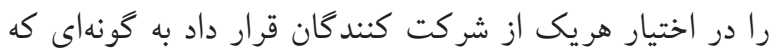

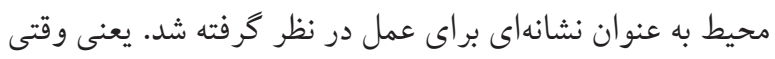

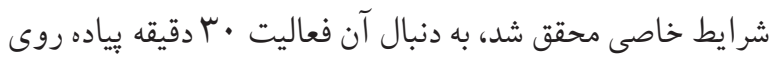

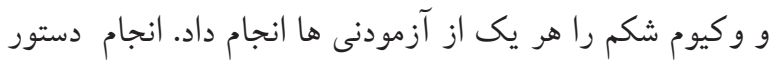

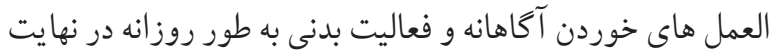

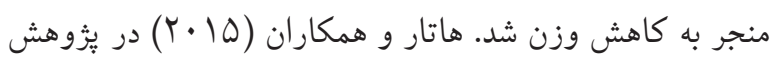

جالش · لم كالرى و توجه و تمر كز به مقدار خوردن توانستند الخوى

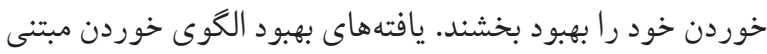

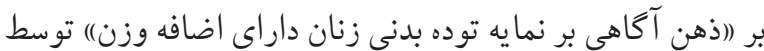

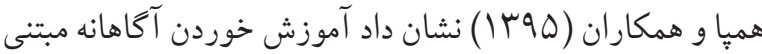
بر ذهن آكاهى باعث كاهش معنى دار نمايه توده بدنى (BMI)

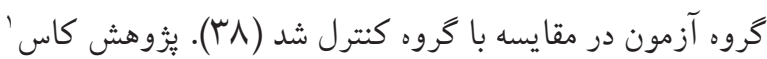

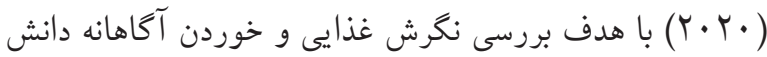
آموزان و همجنين تاثير دانش تغذيه بر خوردن آكاهانه نشان داد داشتن توجه و تمر كز در غذا خوردن به كاهش و حفظ وزن هون

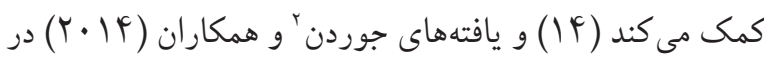

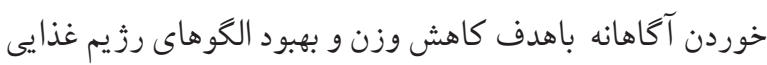
زنان يا ئسه در وعدههاى غذايى كه در رستوران مىخوردند نت نتايج موفقيت آميزى در كاهش وزن داشته است (و (؟). تاثير ذهن اكاهى بر دور كمر در مطالعهاى كاتر و كلى (rV)

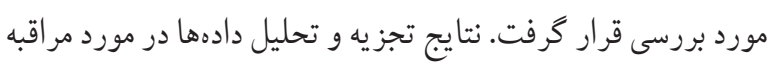
ذهن آكاهى تجارب استرس و ارتباط غذايى مرتبط با استرس رار

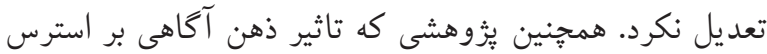

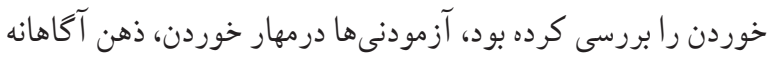
خوردن، عدم توجه به نشانههاى بيرونى در خوردن و اضطر اب بهبود

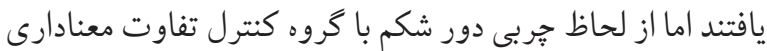

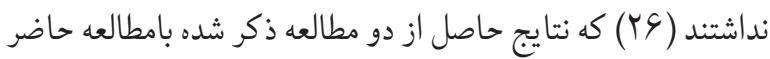

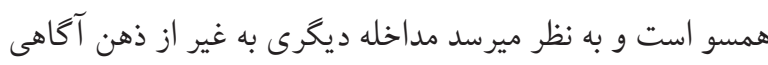

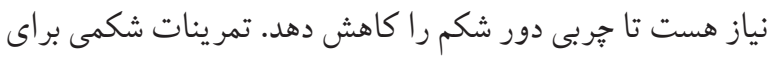

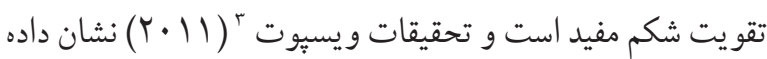

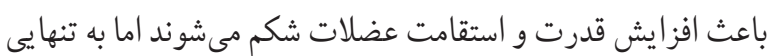

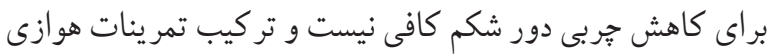

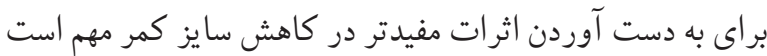

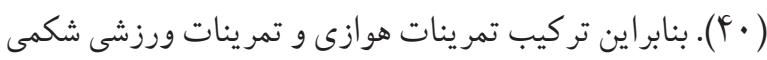

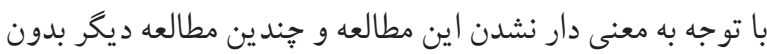


آنجهه در قصد تحقق رفتار به اين آموزش مبتنى بر تمرين اضافه شد،

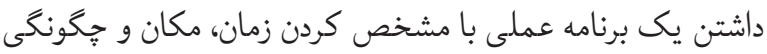
انجام فعاليت بدنى در خارج از جلسات مداخله وحذف تمام موانع جهت عملى كردن اين فعاليت رفتارى بود كه در نهايت اين تلفيق

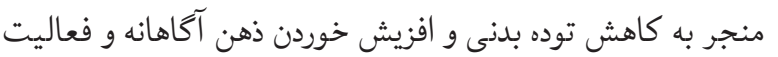
بدنى در گروه آزمون نسبت به گروه كنترل شد.

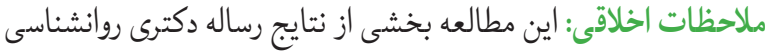

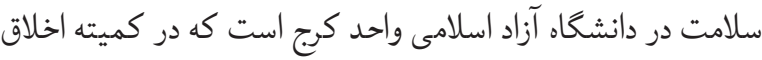
دانشخاه بررسى و تاييد كرديد و شناسه اختصاصى كميته اخلاق و در ثبت كارآزمايى داراى كد دين (IR. IAU. K. REC. 1399.028) مى باشد. به مشاركت كنندگان (IRCT20200919048767N1) در مورد محرمانه بودن مطالب مطرح شده و حفظ بىنامى آنان

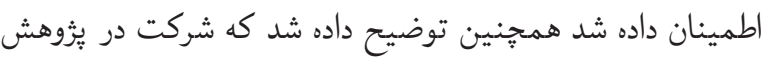

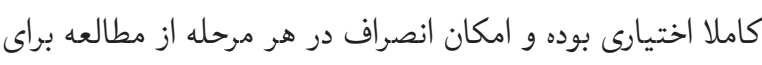

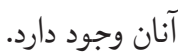

تضاد منافع: هيجگگونه تضاد منافعى در اين مطالعه وجود ندارد. تشكر و قدر دانى از بروفسور جين كريستلر و دكتر آندريا ليبر اشتاين كه شرايط

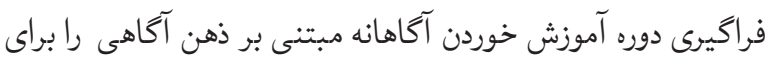
اينجانب فراهم كردند و همجِنين اساتيد ارجمند و شركت كنندكان در يُوهش جهت همكارى تشكر و قدردانى مى شود.

\section{References}

1. Collaborators GO. Health effects of overweight and obesity in 195 countries over 25 years. New England Journal of Medicine. 2017;377(1):13-27. https://doi.org/10.1056/NEJMoa 1614362 PMid:28604169 PMCid:PMC5477817

2. Vahedian-Shahroodi $M$, Tehrani $H$, Robat-Sarpooshi $D$, GHolian-Aval M, Jafari A, Alizadeh-Siuki H. The impact of health education on nutritional behaviors in female students:Anapplication ofhealthbeliefmodel.International Journal of Health Promotion and Education. 2019:1-13. https://doi.org/10.1080/14635240.2019.1696219

3. Horwich TB, Fonarow GC, Clark AL. Obesity and the Obesity Paradox in Heart Failure. Progress
خود نشان دادند مدل قصد تحقق رفتار موجب نتايج اوليه از جمله كاهش وزن و نتايج ثانويه مانند كاهش توده بدنى، نسبت دور كمر - لخن، خودتنظيمى اهداف و برنامه ريزى و رفتارى از جمله ميزان مصرف رزيم غذايى خود گزارش شده و در گيرى در فعاليت

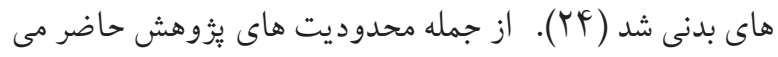

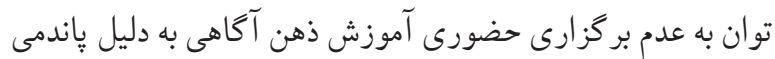
19-COVID

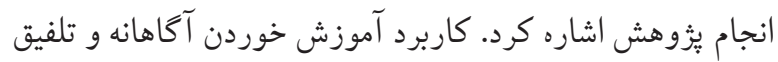
آن با مدل قصد تحقق رفتار به متخصصان فعال در حوزه كاهش بـ هورد

$$
\begin{aligned}
& \text { وزن بيشنهاد مىشود. } \\
& \text { نتيجا، كيرى وزن يبن }
\end{aligned}
$$

بر اساس نتايج حاصل از مطالعه حاضر، و با توجه به اينكه تفاوت معنى دارى بين گروه آزمون و كنترل در شاخص توده بدنى، خوردن

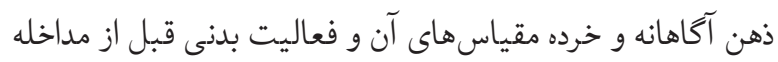
وجود نداشت و بعد از مداخله اين تفاوت معنى دار شده مىتوان

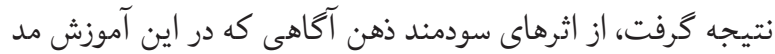
نظر است، بالا بردن توان افراد براى خود تنظيمى است. افزايش خود

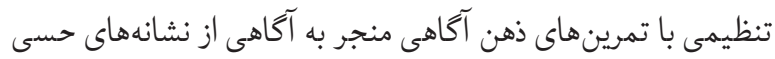

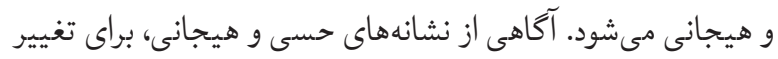

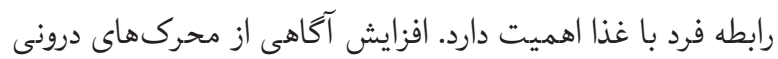
و بيرونى، افزايش دانش تغذيه و معرفى سبك تغذيه سالم اهدافى هستند كه در تماهى جلسات آموزش خوردن آكاهانه دنبال شدند.

in Cardiovascular Diseases. 2018;61(2):151-6. https://doi.org/10.1016/j.pcad.2018.05.005 PMid:29852198

4. Samadbeik M, Saremian M, Sohrabizadeh $M$, Birjandi $M$, Garavand S. Evaluation of E-health literacy in Paramedicine and Health Nutrition students of Lorestan University of Medical Sciences. Journal of Health Literacy. 2020;5(1):1222.

5. Agah Heris M, Alipour A, Janbozorgi M, Mousavi E, Noohi SH. A Comparative Study of Effectiveness on Life- style Modification and Cognitive Group Therapy to Weight Management and Quality of Life Enhancement. Quarterly Journal of Health Psychology. 2012;1(1):68-80. 
6. Folsom $A R$, Kaye $S A$, Sellers $T A$, Hong $C P$, Cerhan JR, Potter JD, et al. Body fat distribution and 5-year risk of death in older women. Jama. 1993;269(4):483-7. https://doi.org/10.1001/jama.269.4.483 https://doi.org/10.1001/jama.1993.03500040049035 PMid:8419667

7. Pouliot MC, Després JP, Lemieux S, Moorjani S, Bouchard C, Tremblay A, et al. Waist circumference and abdominal sagittal diameter: best simple anthropometric indexes of abdominal visceral adipose tissue accumulation and related cardiovascular risk in men and women. The American journal of cardiology. 1994;73(7):460-8. https://doi.org/10.1016/0002-9149(94)90676-9

8. Fruh SM. Obesity: Risk factors, complications, and strategies for sustainable long-term weight management. Journal of the American Association of Nurse Practitioners. 2017;29(S1):S3-s14. https://doi.org/10.1002/2327-6924.12510 PMid:29024553 PMCid:PMC6088226

9. Leehr EJ, Krohmer K, Schag K, Dresler T, Zipfel S, Giel KE. Emotion regulation model in binge eating disorder and obesity--a systematic review. Neuroscience and biobehavioral reviews. 2015;49:125-34.. https://doi.org/10.1016/j.neubiorev.2014.12.008 PMid:25530255

10. Levitan R, Davis R. Emotions and Eating Behaviour: Implications for the Current Obesity Epidemic. University of Toronto Quarterly. 2010;79:783 - 99. https://doi.org/10.3138/utq.79.2.783

11. Salmoirago-Blotcher E, DrukerS, Meyer F, BockBC, Crawford S, Pbert L. Design and methods for "Commit to Get Fit" a pilot study of a school-based mindfulness intervention to promote healthy diet and physical activity among adolescents. Contemporary clinical trials. 2015;41:248-58. https://doi.org/10.1016/j.cct.2015.02.004 PMid:25687667 PMCid:PMC4380800

12. Nezlek JB, Holas P, Rusanowska M, Krejtz I. Being present in the moment: Event-level relationships between mindfulness and stress, positivity, and importance. Personality and Individual Differences. 2016;93:1-5. https://doi.org/10.1016/j.paid.2015.11.031

13. Moor, K. R., Scott, A. J., \& McIntosh, W. D. Mindful eating and its relationship to body mass index and physical activity among university students. Mindfulness.2013; 4: 269-274. https://doi.org/10.1007/s12671-012-0124-3

14. Köse G, Tayfur M. BMI, Physical Activity, Sleep Quality, Eating Attitudes, Emotions: Which One is Affected by Mindful Eating? Progress in Nutrition. 2021;23:0-00.
15. Sarto, H.M. Soler, A.B. Mercadal, P.H. Pantilie, B. NavarroGil, M. Garcia-Campayo, J. Montero-Marin, J.(2019). Efficacy of a mindful-eating programmer to reduce emotional eating in patients suffering from overweight or obesity in primary care settings: a cluster-randomised trial protocol. BMJ Open:2019; first published as 10.1136/ bmjopen-2019-031327.

16. Kristeller JL, Wolever RQ. Mindfulness-based eating awareness training for treating binge eating disorder: the conceptual foundation. Eating disorders. 2011;19(1):49-61. https://doi.org/10.1080/10640266.2011.533605 PMid:21181579

17. O'Reilly GA, Cook L, Spruijt-Metz D, Black DS. Mindfulness-based interventions for obesity-related eating behaviours: a literature review. Obesity reviews: an official journal of the International Association for the Study of Obesity. 2014;15(6):453-61. h tt p s: / / d o i.org / 10.1111 / obr. 12156 PMid:24636206 PMCid:PMC4046117

18. Köse G, Çıplak ME. Mindful eating questionnaired: eating control, emotional eating and conscious nutrition trio: Mindful Eating Eating Control, Emotional Eating, Conscious Nutrition. Progress in Nutrition. 2020;22(2):555-61.

19. Webb, T. L., \& Sheeran, P. Does changing behavioral intentions engender behavioral change? A meta-analysis of the experimental evidence. Psychological Bulletin.2006; 132, 249-268. https://doi.org/10.1037/0033-2909.132.2.249 PMid:16536643

20. Gollwitzer, P.M. Goal Achievement: The Role of Intentions. In W. Strobe and M.Hestone (Eds) European Review of Social Psychology.1993; Vol. 4.Chicester: Wiley, 141-148. https://doi.org/10.1080/14792779343000059

21. Ajzen, I. The theory of planned behavior. Organizational Behaviorand Human Decision Processes. 1991;50, 179-211. https://doi.org/10.1016/0749-5978(91)90020-T

22. Aarts, H., Gollwitzer, P. M., \& Hassin, R. R. Journal of Social Psychology. 2004; 87, 23-37. https://doi.org/10.1037/0022-3514.87.1.23 PMid:15250790

23. Abraham, C.and Sheeran, P. (2004).Implications of goal theories for the theorise of reasoned action and planned behaviour, Current Psychology. 2004; 22,218-233 https://doi.org/10.1007/s12144-003-1021-7

24. Hattar A, Hagger MS, Pal S. Weight-loss intervention using implementation intentions and mental imagery: a randomised control trial study protocol. BMC public health. 2015;15:196. 
https://doi.org/10.1186/s12889-015-1578-8 PMid:25879572 PMCid:PMC4363065

25.CooperZ,DollHA,HawkerDM, ByrneS, BonnerG, EeleyE,etal. Testing a new cognitive behavioural treatment for obesity: A randomized controlled trial with three-year follow-up. Behaviour research and therapy. 2010;48(8):706-13. https://doi.org/10.1016/j.brat.2010.03.008 PMid:20691328 PMCid:PMC2923743

26. Daubenmier J, Moran PJ, Kristeller J, Acree M, Bacchetti P, Kemeny ME, etal. Effects of a mindfulness-based weight loss intervention in adults with obesity: A randomized clinical trial. Obesity (Silver Spring, Md). 2016;24(4):794-804. h tt p s : / / d o i . org / 10.1002 / oby. 21396 PMid:26955895 PMCid:PMC4898945

27. Milne, S, .Orbell, S. and Sheeran, P. Combining motivational and volitional interventions to promote exercise participation: protection motivation theory and implementation intentions. $\mathrm{Br} J$ Health Psychol. 2002 May; 7(Pt 2):163-84. https://doi.org/10.1348/135910702169420 PMid:14596707

28. Fesharaki MG, Kazemnejad A, Zayeri F, Sanati J, Akbari H. Historical cohort study on the factors affecting blood pressure in workers of polyacryl iran corporation using bayesian multilevel modeling with skew $\mathrm{T}$ distribution. Iranian Red Crescent Medical Journal. 2013;15(5):418. htt p s : / / o i . org / 10.5812 / ircm j. 10930 PMid:24349731 PMCid:PMC3838653

29. VanVoorhis CRW, Morgan BL. Understanding power and rules of thumb for determining sample sizes. Tutorials in Quantitative Methods for Psychology 2007;3(2):43-50. https://doi.org/10.20982/tqmp.03.2.p043

30. Lean ME, Han TS, Morrison CE. Waist circumference as a measure for indicating need for weight management. BMJ (Clinical research ed). 1995;311(6998):158-61. https://doi.org/10.1136/bmj.311.6998.158 PMid:7613427 PMCid:PMC2550221

31. Vispute SS, Smith JD, LeCheminant JD, Hurley KS. The effect of abdominal exercise on abdominal fat. Journal of strength and conditioning research. 2011;25(9):2559-64. https://doi.org/10.1519/JSC.0b013e3181fb4a 46 PMid:21804427

32. Framson C, Kristal AR, Schenk JM, Littman AJ, Zeliadt S, Benitez D. Development and validation of the mindful eating questionnaire. Journal of the American Dietetic Association. 2009;109(8):1439-44 https://doi.org/10.1016/j.jada.2009.05.006 PMid:19631053 PMCid:PMC2734460

33. Pondeh Nezhadan AA, Attari Ya, Hussein D. Factorial Structure and Reliability of Eating Mindfully Questionnaire (EMQ) among Married Women with Overweight and Obesity. Jundishapur Scientific Medical Journal. 2018;17(2):131-43.

34. Kristeller JL, Jordan KD. Mindful Eating: Connecting With the Wise Self, the Spiritual Self. Front Psychol. 2018;9:1271-. https://doi.org/10.3389/fpsyg.2018.01271 PMid:30154740 PMCid:PMC6102380

35. Katterman SN, Kleinman BM, Hood MM, Nackers LM, Corsica JA. Mindfulness meditation as an intervention for binge eating, emotional eating, and weight loss: a systematic review. Eating behaviors. 2014;15(2):197-204. https://doi.org/10.1016/j.eatbeh.2014.01.005 PMid:24854804

36. Cotter EW, Kelly NR. Stress-related eating, mindfulness, and obesity. Health Psychol. 2018;37(6):516-25. htt p s : / / o i . org / 10.1037 / h e a 0000614 PMid:29708389 PMCid:PMC6488023

37. Daubenmier J, Kristeller J, Hecht FM, Maninger N, Kuwata M, Jhaveri K, et al. Mindfulness Intervention for Stress Eating to Reduce Cortisol and Abdominal Fat among Overweight and Obese Women: An Exploratory Randomized Controlled Study. Journal of obesity. 2011;2011:651936. https://doi org/10.1155/2011/651936 PMid:21977314 PMCid:PMC3184496

38. Oraki M, Ghorbani M. The Effectiveness of MindfulnessBased Eating Awareness Training (MB-EAT) on Perceived Stress and Body Mass Index in Overweight Women. International Journal of Applied Behavioral Sciences. 2019;6(3):1-8.

39. Jordan CH, Wang W, Donatoni L, Meier BP. Mindful eating: Traitandstatemindfulness predicthealthiereating behavior. Personality and Individual Differences. 2014;68:107-11. https://doi.org/10.1016/j.paid.2014.04.013

40. Gharib NM. Vacuum Therapy Versus Abdominal Exercises on Abdominal Obesity. International journal of physiotherapy. 2016;3. https://doi.org/10.15621/ijphy/2016/v3i3/100827 